\title{
Adaptive Expectations versus Rational Expectations: Evidence from the lab
}

\author{
Annarita Colasante ${ }^{1}$, Antonio Palestrini, Alberto Russo, Mauro Gallegati \\ Università Politecnica delle Marche, Piazzale Martelli 8, Ancona, Italy.
}

\begin{abstract}
The aim of the present work is to shed light on the extensive debate about expectations in financial market. We analyze the behavior of subjects in an experimental environment in which it is possible to directly observe expectations since the sole task of each player is to predict the future price of an asset. We investigate the mechanism of expectation formation in two different contexts: in the first, the fundamental value is constant; in the second, the fundamental price increases over repetitions. First of all we observe if, according to the main results shown in Palestrini and Gallegati (2015), there is a convergence to the rational equilibrium even if agents have adaptive expectations. Moreover, we concentrate on the accuracy of aggregate forecasts compared with the individual forecasts. We find that there is collective rationality instead of individual rationality. In the context of increasing fundamental value, contrary to the theoretical predictions, players are able to capture the trend but they underestimate that value. This implies that if all agents make their forecasts according to an adaptive scheme, there is no full convergence to the rational expectations equilibrium.
\end{abstract}

Keywords:

Price forecasting, Financial market, Experiment, Panel data, Forecasting practice

\section{Introduction}

The recent financial crisis highlighted the importance of agents' behaviour in the financial market and, in turn, the impact of individual financial choices in the real economy. Agents make their everyday choices based on their expectations. As suggested in Assenza et al. (2014), we should think of an economy as an expectation feedback mechanism in which expectations influence individual decisions and these choices define the realisation of the main macro or financial variables.

\footnotetext{
${ }^{1}$ Corresponding Author. E-mail: colasante.a84@gmail.com. Present Address: University Jaume I, Castellón de la Plana, Spain.
} 
The present work analyses individual behaviour in an experimental asset market in which the sole task of each player is to predict the future price of an asset, based on two sources of information: $i$ ) the past realization of the asset price in the market, which is a function of the average individual expectations, and $i i$ ) the current information about the mean dividend and the interest rate. We run two different treatments in which the only difference is the fundamental price. Each treatment involves six groups of six players. In the Treatment 1 the fundamental price is constant and equal to 60, while in Treatment 2 the fundamental price increases over repetitions. The aim of this work is to understand how agents form their expectations about future prices and we seek to understand if, even in absence of communication, aggregate expectations are unbiased. The key difference with respect to the existing literature is that we analyse expectation formation in a context characterised by price instability. The only contribution in which an increasing fundamental is presented is the work by Noussair and Powell (2010) but their focus is bubble formation in an asset market with trade. We take into account a dividend with a drift in order to analyse the mechanism of the error correction bias. This theoretical approach is based on the evidence that Rational Expectations are mean-zero expectation schemes. On the contrary, even though adaptive expectation schemes often seem to be an accurate representation of actual agent behaviours in an empirical analysis (see Chow (2011)), this scheme does not seem to satisfy the unconditional mean-zero requirements, i.e., the necessary condition for rationality. The idea behind the error correction is to include a term in the adaptive expectation scheme to fulfil the requirement of the zero unconditional mean. We discuss this approach in more detail in Section 2.

We use the Learning-to-Forecast Experiment to analyse not only the forecast ability of players but also the level of coordination in the group. Indeed, each player must predict the price that, in turn, depends on the expectations of other players. This means that players should forecast an endogenous price and, to do so, they must be able to infer the predictions of other participants.

The Rational Expectation Hypothesis (REH), firstly introduced by Muth (1961) and then analysed in detail by Lucas Jr and Prescott (1971), is the bearing-wall of the mainstream approach. According to this hypothesis, agents make no systematic errors in forecasting, taking into account the entire set of available information $^{2}$. Muth takes into account the early work of Galton (1907) in which it is

\footnotetext{
${ }^{2}$ In Muth the analysis is based on 3 assumptions: 1) Information is scarce, and the economic system generally does not waste it; 2) The way expectations are formed depends specifically on the structure of the relevant system describing the economy; 3) A "public prediction", in the sense of Grunberg and Modigliani (1954), will have no substantial effect on the operation of the economic system (unless it is based on inside information). Muth at pg. 317 stresses, in a sense, that the rational expectation hypothesis is made only to represent the heterogeneous behaviours
} 
pointed out that individual expectations are wrong, but that aggregating individual predictions can render unbiased expectations. Recent studies, based on both simulation and experimental evidence, show that this approach is often unrealistic, that is agents do not have sufficient capabilities to make rational predictions (see, for example, (Sargent, 1993), Evans and Honkapohja (2001) and Branch (2004)). An alternative hypothesis is that agents form their expectations based on an adaptive rule, namely that the forecast is a function of both past expectations and past realisation.

The mainstream approach does not deem the adaptive expectation scheme to be appropriate to forecast models since it may not satisfy the necessary condition for rationality. This condition is based on the assumption that agents make nonsystematic prediction errors and, as a result, the errors' unconditional mean is equal to zero. The increasing experimental evidence (Hommes (2011), Anufriev and Hommes (2012)) shows that individuals make forecasting errors in predicting the future value of an assets or the price of a commodity. Moreover, it has been shown that a combination of different forms of adaptive expectation rules produces a process that fits very well with the experimental data.

In this work we introduce the possibility of revising the classical adaptive expectation scheme in order to achieve the condition of zero unconditional mean. We propose a theoretical model to prove that, if we introduce bias correction parameters in the baseline scheme, then the unconditional mean is equal to zero. Indeed, it can be proved that this correction does not alter the stability of the system, but rather increases the volatility of variables. This mechanism introduce a a trade- off between volatility and bias that can be analyzed in detail in the model validation step of an economic analysis.

The paper is organised as follows: in Section 2 we introduce the error correction approach, in Section 3 we describe the experiment and the main results. Expectations are analysed in Section 4, while in Section 5 we check the error correction bias in our setting. Finally, a conclusion is provided in Section 6 whilst Appendix A describes the experimental instructions.

\section{Error correction mechanism}

In this Section we show how the adaptive expectation scheme, under certain assumptions, should satisfy the rationality condition, i.e. the zero unconditional mean. Usually people show behaviour consistent with the Adaptive expectation (Nerlove (1958)). This means that agents adjust expectations in $t+1$ comparing

of entrepreneurs: "It does not assert that the scratch work of the entrepreneurs resembles the system of equations in any way; nor does it state that predictions of entrepreneurs are perfect or that their expectations are all the same". 
expectations in $t$ with the price information set available in period $t$. In the classic Nerlove's work the price information set is the realized price at time $t$ whereas, in our experiment, we follow the Hommes et al. (2005) line of research in which agent's information set is the realized price at time $t-1$. In the rest of this Section, for the sake of explanation, we follow the Nerlove's convention. In this case, agents look at the past realisation of the price $\left(p_{t}\right)$ and try to correct their forecasting errors $\left(p_{t-1}^{e}\right)$ in each period. The expected price can be written as

$$
p_{t+1}^{e}=p_{t}^{e}+\lambda\left(p_{t}-p_{t}^{e}\right) \quad 0<\lambda \leq 1
$$

or it can be rewritten as a linear combination of past realisation and past prediction:

$$
p_{t+1}^{e}=\lambda p_{t}+(1-\lambda) p_{t}^{e}
$$

The formulation in Equation 1 suggests that agents make systematic forecasting error $\left(p_{t}-p_{t-1}^{e}\right)$ and, moreover, that they include this error in their own future predictions. This implies that individuals should underestimate (overestimate) the realized price because of this correction mechanism. Taking into account this definition, it is possible to assert that adaptive expectation schemes may generate a bias ${ }^{3}$. Indeed, adaptive expectation are backward looking because they only take into account past information to predict future values. For example, if agents use as an expectation of variable $x_{t}$ the mean of the past 3 periods is:

$$
x_{t+1}^{e}=\frac{1}{3}\left(x_{t}+x_{t-1}+x_{t-2}\right)
$$

and the variable has a drift, say $\Delta x_{t+1}=d$, then the error/bias $\Xi_{t+1}=x_{t+1}^{e}-x_{t+1}$ is

$$
\begin{gathered}
\Xi_{t+1}=\frac{1}{3}\left(\left(x_{t-2}+2 d\right)+\left(x_{t-2}+d\right)+x_{t-2}\right)-\left(x_{t-2}+3 d\right) \\
\Xi_{t+1}=\left(x_{t-2}+d\right)-\left(x_{t-2}+3 d\right)=-2 d
\end{gathered}
$$

By analysing this simple example, two interesting aspects ${ }^{4}$ that will be tested emerge:

1. The bias is negative (expectation is below if variable trends up and above if trends down)

\footnotetext{
${ }^{3}$ This is the reason for introducing rational expectations in macroeconomic models within the determinate parametric space (Blanchard and Kahn (1980)).

${ }^{4}$ Notice that, even if we consider a different timing, meaning $x_{t+1}^{e}=\frac{1}{3}\left(x_{t-1}+x_{t-2}+x_{t-3}\right)$ the main results remain unchanged. In fact, we obtain that $\Xi_{t+1}=-3 d$.
} 
2. The bias has an order of magnitude comparable to the drift.

On the contrary, as discussed in the introduction, Galton's discovery suggests that agents, collectively and in simple situations, are able to estimate unconditional means.

This condition of a mean-zero error may be a problem in adaptive expectations schemes, as the above simple example suggests, since it could produce agent's expectation that over or underestimates the future value of economic variables; i.e., with a non-zero bias.

Consider the time process of the error

$$
\Xi_{t}=x_{t}^{e}-x_{t}=\lambda x_{t-1}+(1-\lambda) x_{t-1}^{e}-x_{t}
$$

that, adding and subtracting $x_{t-1}$ from the RHS and rearranging terms, may be written as

$$
\Xi_{t}=x_{t}^{e}-x_{t}=(1-\lambda)\left[x_{t-1}^{e}-x_{t-1}\right]-\Delta x_{t}
$$

with the following recursive $\mathrm{AR}(1)$ structure

$$
\Xi_{t}=(1-\lambda) \Xi_{t-1}-\Delta x_{t}
$$

Now it is easy to see that even in situations in which the $x_{t}$ variable follows a very simple deterministic process, $\Delta x_{t}=d$ (as is the case in Treatment 2 described in Section 3), the error process

$$
\Xi_{t}=(1-\lambda) \Xi_{t-1}-d
$$

does not go to zero, but converges to $\Xi=-d / \lambda$.

Furthermore, many econometric studies show that even in situations in which the adaptive expectation process seems to be a reasonable representation of agents' behaviour (Chow (2011)), the parameter $\lambda$ may be time variant.

What do agents have to do to correct for this bias? Following the analysis in Palestrini and Gallegati (2015), consider the following generalisation of the adaptive scheme

$$
x_{t+1}^{e}=\lambda_{t} x_{t}+\left(1-\lambda_{t}\right) x_{t}^{e}+\zeta_{t} .
$$

Equation (7) generalizes the standard adaptive scheme in two respects: $i$ ) It has a time varying learning parameter $\lambda_{t}$ following an i.i.d. random process (between 0 and 1 ) with mean $1-\lambda$, and $i$ ) there is a bias correction parameter, $\zeta$.

As before, we can compute the error process as:

$$
\Xi_{t+1}=x_{t+1}^{e}-x_{t+1}=\lambda_{t} x_{t}+\left(1-\lambda_{t}\right) x_{t}^{e}+\zeta_{t}-x_{t+1}
$$


and add and subtract $x_{t}$ to the RHS,

$$
\Xi_{t+1}=-\left(1-\lambda_{t}\right) x_{t}+\left(1-\lambda_{t}\right) x_{t}^{e}+\zeta_{t}-\Delta x_{t+1}
$$

that simplifies to $^{5}$

$$
\Xi_{t+1}=\left(1-\lambda_{t}\right) \Xi_{t}+\zeta_{t}-\Delta x_{t+1}
$$

Equation (10) is a stochastic random difference process that has a stationary solution provided that the stability conditions are met $^{6}$.

If an unconditional expectation exists we can take the unconditional expectation operator on both sides and equate to zero by searching for a solution with $E\left[\Xi_{t+1}\right]=0$, that is

$$
(1-\lambda) 0+\zeta_{t}-E\left[\Delta x_{t+1}\right]=0 .
$$

Solving for $\zeta_{t}$ we get

$$
\zeta_{t}=E\left[\Delta x_{t+1}\right]
$$

showing that, to perfectly correct for the bias, agents individually (time series dimension) or collectively (cross series dimension) must estimate the drift of the economic variable for which there are expectations.

Summing up, if agents are able to estimate the trend of the variable, they should take into account this information to form their expectations. Including an unbiased estimated value of the drift in the expectation process, i.e. the term $\zeta_{t}$, leads to unbiased forecasts even in the case of adaptive expectations.

\section{Learning to Forecast in a financial market}

\subsection{Description of the Experiment}

We run a Learning to Forecast experiment based on Asset Pricing Model (Campbell et al. (1997)) to understand the mechanism of expectation formation in a financial market. In this model there is a single security with a dividend $d_{t}$ and a price $p_{t}$, and a risk-free asset that pays a constant rate $R=1+r$ units per period. The dividends are usually ${ }^{7}$ an i.i.d. variable with mean $\bar{d}$, so the fundamental price is represented by $p^{f}=\frac{\bar{d}}{r}$.

Following the approach proposed in Hommes et al. (2005), we include stabilizing fundamentalist robots. The sole task of players is to predict the future price of the asset knowing the mean dividend $\bar{d}$ and the interest rate $r$. In particular, in

\footnotetext{
${ }^{5}$ In the case in which $\lambda_{t}=1$ (static expectation), the error process is, obviously, $\Xi_{t+1}=$ $\zeta_{t}-\Delta x_{t+1}$.

${ }^{6}$ See Babillot et al. (1997), and Bhattacharya and Majumdar (2007) p. 304.

${ }^{7}$ In our experiment the dividend is an i.i.d. process only in the first treatment.
} 
the first and second periods, participants have no information about the market price and about their profit. In these two periods we impose an upper bound of 100 to their predictions. From the third repetition, participants are able to see the realised price until period $t-1$ and their own forecast and they must predict the future price of the option $p_{t+1}^{e}$. Moreover, the upper bound we set up at the beginning was taken out so that subjects could insert any value. Figure 1 depicts the experimental computerized screen. We consider a small group of investors, i.e. 6 people, who make predictions over 51 periods.

The existing literature devoted to the analysis of expectations in the lab should be divided into three main categories. The first, proposed by Smith et al. (1988), consists of a double auction market in which players buy and sell assets. From this kind of experiment, proposed also in Noussair et al. (2001), Dufwenberg et al. (2005) and Kirchler (2009), two main results emerges: 1) players usually follow an adaptive rule to form their forecasts; 2)a lot of bubbles emerge if players have no experience in this setting. The main disadvantage of this method is that expectations are inferred and not directly observable. The pioneer work of the second category is that by Dwyer et al. (1993). In this experiment players predict the future price of an exogenous series, i.e. the time series of the asset price is generated ex ante and the individual predictions do not influence the realization of the series. Bloomfield and Hales (2002) and Dwyer et al. (1993) propose an experiment in which the series is a random walk, while Hey (1994) proposed an autoregressive process. Results of this kind of analysis are mixed, meaning that some players behave rationally while other use an adaptive expectation scheme. The limitation of this setting is related to the independence of individual expectations and the realisation of the future price. Finally, the third category includes the so-called Learning to Forecast experiments proposed by Marimon et al. (1993) in which the task is to forecast the future price of an endogenous series. This means that the realized price is a function of the individual forecasts, i.e. the market is an expectations feedback mechanism. The literature provides numerous contributions in this field, using both negative (Hommes et al. (2007), Bao et al. (2012)) and positive (Hommes et al. (2005), Bottazzi et al. (2011), Anufriev and Hommes (2012)) feedback system. Moreover, a more recent strand of literature propose the so-called "Learning to Optimize" (Bao et al. (2013), Bao et al. (2014)) in which subjects make the best choice in terms of productions (for a comparison of these methods see Duffy (2010)). Evidence from these experiments suggests that, in general, there is strong coordination in the group and that there is convergence to the rational equilibrium only if we consider negative feedback. See Hommes (2014) for an exhaustive review of the main results of the Learning to Forecast experiments.

In our experiment we consider two different treatments: i) Treatment 1 in 


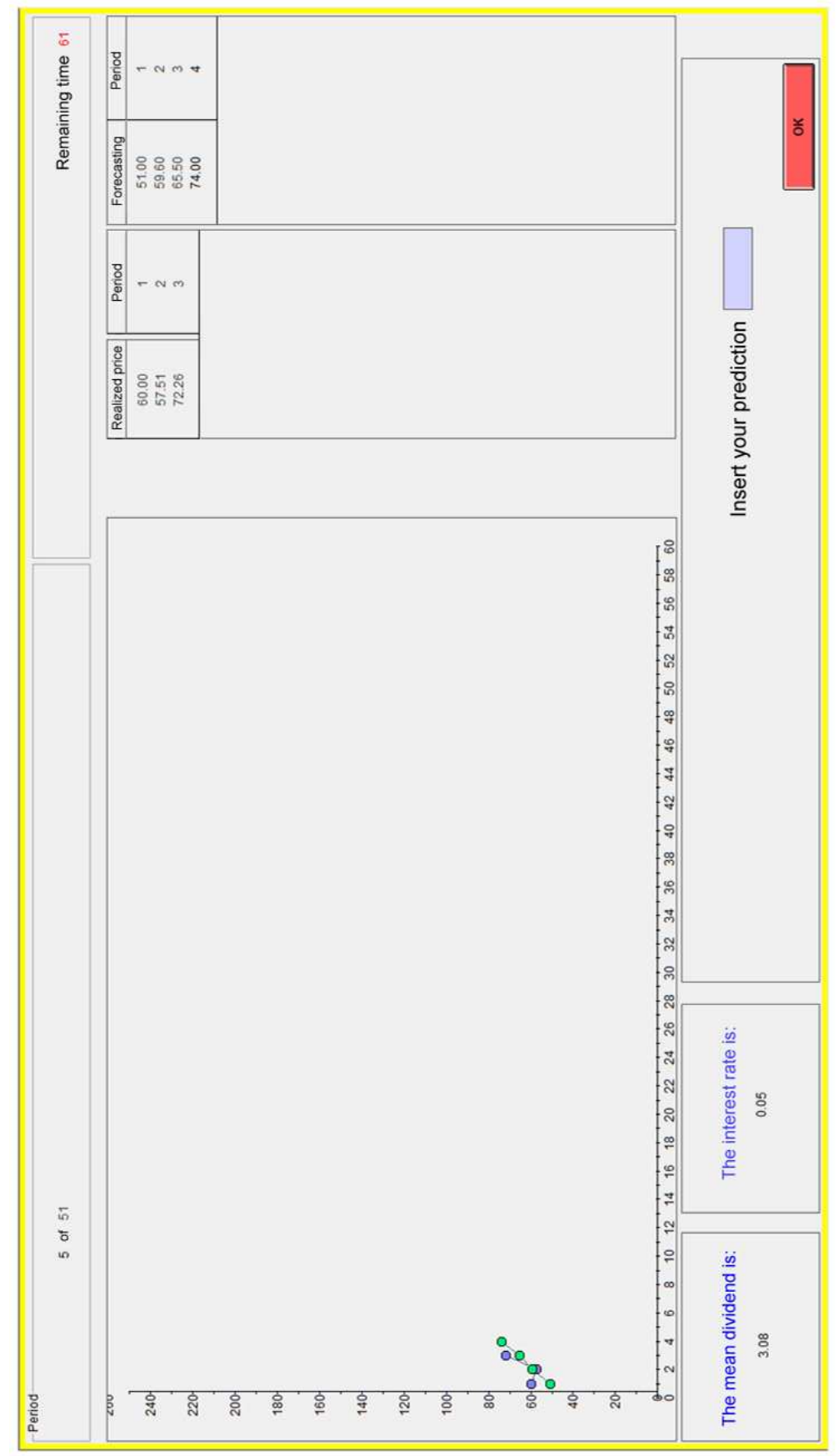

Figure 1: The screen-shot of the experiment in Treatment 1 
which the mean dividend, and so the fundamental price, remains constant over repetition; ii) Treatment 2 in which the mean dividend follows an increasing linear trend. In both treatments we assume that agents are myopics so that they know the only the dividend of the current period.

Participants in the experiment are divided into groups of six and receive only qualitative information. Players know that they are advisor of a pension fund and these funds take into account their predictions to decide how best to invest their money between a risk-free asset and a risky option. They do not know the equation that determines the price but do know that the price is provided by the equilibrium between supply and demand and they are informed about the mean dividend and the interest rate. Taking into account this information, agents can compute, and hence predict, the fundamental price. Moreover, they also know that the higher their predictions, the higher the realised price will be.

According to Brock and Hommes (1998), the equation for determining the market price corresponds to the market clearing equilibrium. The theoretical model suggests that each agent, in each period, chooses how much to invest in the risky asset according to a maximization of his/her own future expected wealth. This means that the demand for the risky asset derives from utility maximization. By equating supply and demand, we obtain the equilibrium price given by:

$$
p_{t}=\frac{1}{1+r}\left[\bar{p}_{t+1}^{e}+\bar{d}_{t}+\varepsilon_{t}\right]
$$

where $r$ is the interest rate, $\bar{p}_{t+1}^{e}$ is the average predicted price, $\bar{d}_{t}$ is the mean dividend and $\varepsilon_{t}$ is a small normal shock.

Following the same approach in Hommes et al. (2005), we consider a fraction of computerized fundamentalist computer traders $n_{t}$ in our setting. The equation used for the determination of price is the following :

$$
p_{t}=\frac{1}{1+r}\left[\left(1-n_{t}\right) \bar{p}_{t+1}^{e}+n_{t} p_{t}^{f}+\bar{d}_{t}+\varepsilon_{t}\right]
$$

where $n_{t}$ is the share of fundamentalist robots in each period. This means that the price is a weighted average between the predicted price by each group and the fundamental price, plus a small shock.

The share of robot traders 8 is a function of the absolute distance between the realised market price and the fundamental price. According to Hommes et al.

\footnotetext{
${ }^{8}$ According to Assenza et al. (2014), robot fundamentalists are useful to avoid there being an explosive price increase, as the large bubbles shown in Hommes et al. (2008). Moreover, since this kind of traders asserts that the deviation from the fundamental price is only temporary, the share of fundamentalists increases with the distance between the realised price and the rational equilibrium.
} 
(2005), the share of these traders is defined by the following equation:

$$
n_{t}=1-\exp \left(-\frac{1}{200}\left|p_{t-1}-p_{f}\right|\right)
$$

According to Equation (15), as the price diverges from the fundamental, the number of fundamentalists increases. This mechanism is useful to avoid the creation of bubbles in the market ${ }^{9}$.

Following the approach of Hommes (2013), the payoff function depends on the distance between the individual prediction and the realised market price, as in equation (16):

$$
\begin{cases}\pi_{i t}=\left(1-\frac{\left(p_{t}-p_{i t}^{e}\right)^{2}}{7}\right) & \text { if }\left|p_{t}-p_{i t}^{e}\right|<7 \\ \pi_{i t}=0 & \text { otherwise }\end{cases}
$$

The experiment involves in total 72 participants ( 37 female), half of which plays in Treatment 1. In both treatments we randomly allocate players in groups of 6 . We consider $r=5 \%$ and the small shock is such that $\varepsilon \sim N(0,0.25)$. In Treatment 1 , the mean dividend is constant $\bar{d}$ hence the fundamental price is equal to $p^{f}=60$. In Treatment 2, the mean dividend increases step-by-step by 0.02 . This means that $\bar{d}_{t} \in[3,4]$ and so the fundamental price ranges from 60 to 80 . As we said, we assumed that agents are myopics and this implies that they are not aware of the whole trend from the beginning of the game. On the contrary, they are able to see only the single period increase equal to 0.02. The experiment was conducted in October 2014 in the lab of the Faculty of Economics of the Polytechnic University of Marche using the software $z$-tree (Fischbacher (2007)). We randomly drew 72 Economics students from a population of 390 registered participants sending an invitation e-mail. The students were invited to show-up in the Laboratory of the Faculty of Economics to participate in the experiment. Each session lasted for about 90 minutes and participants were paid in cash at the end of each session. During the game, prices were expressed in ECU (Experimental Currency Unit). At the beginning of each session, the organizers read aloud the general instructions and the players read the specific instructions on their respective screen. The final payment depended on the final gains earned in the game. The mean earning per player was equal to 15 Euro (the exchange rate being 1 Euro $=4$ ECU), including

\footnotetext{
${ }^{9}$ Hommes et al. (2005) ran the same experiment with and without the robot traders and they demonstrated that there is no significant difference between these settings. Moreover, the manner in which bubbles emerge in the financial markets emerge is an interesting topic that is, unfortunately, out of the scope of this analysis.
} 
Table 1: Test of comparison between the realized price and the fundamental value

\begin{tabular}{lcccc|ccccc}
\hline & \multicolumn{4}{c}{ Treatment 1} & \multicolumn{5}{c}{ Treatment 2} \\
\hline Group & $\mathrm{t}$ & $\mathrm{p}$-value & $\mathrm{z}$ & $\mathrm{p}$-value & Groups & $\mathrm{t}$ & $\mathrm{p}$-value & $\mathrm{z}$ & $\mathrm{p}$-value \\
\hline 1 & -14.89 & $<0.01$ & -13.411 & $<0.01$ & 1 & -41.45 & $<0.01$ & -15.079 & $<0.01$ \\
2 & -28.23 & $<0.01$ & -15.162 & $<0.01$ & 2 & -17.80 & $<0.01$ & -13.427 & $<0.01$ \\
3 & 14.25 & $<0.01$ & 11.000 & $<0.01$ & 3 & -66.20 & $<0.01$ & -15.162 & $<0.01$ \\
4 & 7.73 & $<0.01$ & -6.098 & $<0.01$ & 4 & -56.78 & $<0.01$ & -15.162 & $<0.01$ \\
5 & 27.70 & $<0.01$ & 14.225 & $<0.01$ & 5 & -43.85 & $<0.01$ & -15.162 & $<0.01$ \\
6 & 42.19 & $<0.01$ & 14.880 & $<0.01$ & 6 & -73.71 & $<0.01$ & -15.162 & $<0.01$ \\
\hline
\end{tabular}

the show-up fee ${ }^{10}$. A summary of the instructions and and the average payment per group is provided in the Appendix A.

\subsection{Summary of the main results}

On the left panel of Figures 2, 3, 4 and 5 we observe agents' predictions with respect to the realised price. On the right panel we show the predictions after period 15, i.e. after the learning period ${ }^{11}$.

It should be noted that, under the Rational Expectation Hypothesis, individual predictions should be equal to the value of $p^{f}$, which is represented by the continuous grey line in all of the Figures. At a glance, none of the groups converge to the fundamental price in both treatments ${ }^{12}$. We ran a t-test and a Wilcoxon test to investigate whether the difference between the fundamental value and the realised price is statistically significant. Results are shown in Table 1. Both the parametric and non-parametric tests confirm that the realised price is different from the fundamental value in all groups.

In Treatment 1, two groups converge quickly to an equilibrium price that is very close to the fundamental value. Three groups overestimate the fundamental price and Group 4 converge very slowly to a price close to the fundamental value. In Treatment 2 agents make their predictions following the increasing trend of the fundamental price, but systematically underestimate the magnitude of the drift. In particular, Group 5 and Group 6 show the highest and quickest coordination, and the series of realised prices in Group 5 is very close to the fundamental price. In Groups 1, 2 and 3 there is at least one player who makes odd predictions also after

\footnotetext{
${ }^{10}$ We give also an extra- bonus to participants who collect perfect prediction in each peri od.

${ }^{11}$ In Figure 3, subfigure (b) and in Figure 4, subfigure (d) we omitted the extreme predictions for a better view of the individual behaviour.

${ }^{12}$ It is important to underline that the role of the fundamentalist robot traders was marginal since the maximum share was equal to $15 \%$.
} 


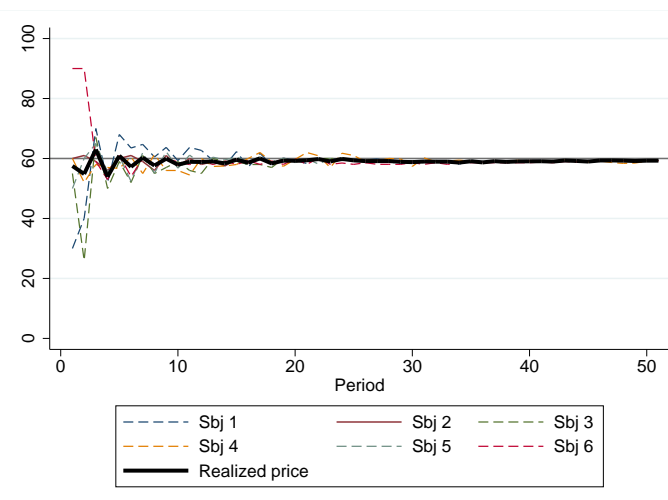

(a) Group 1

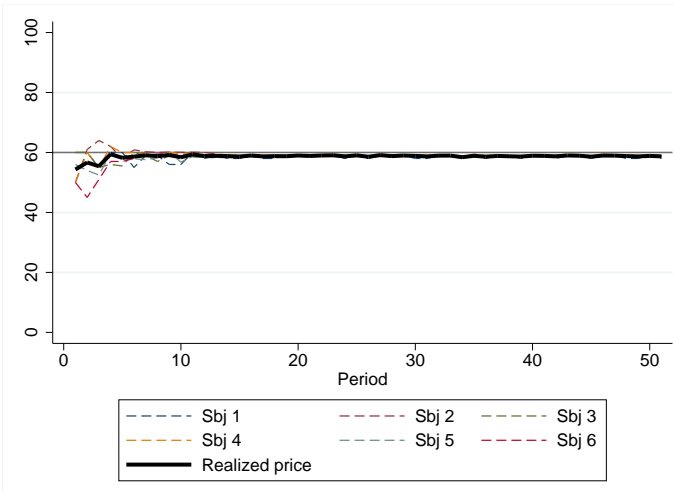

(c) Group 2

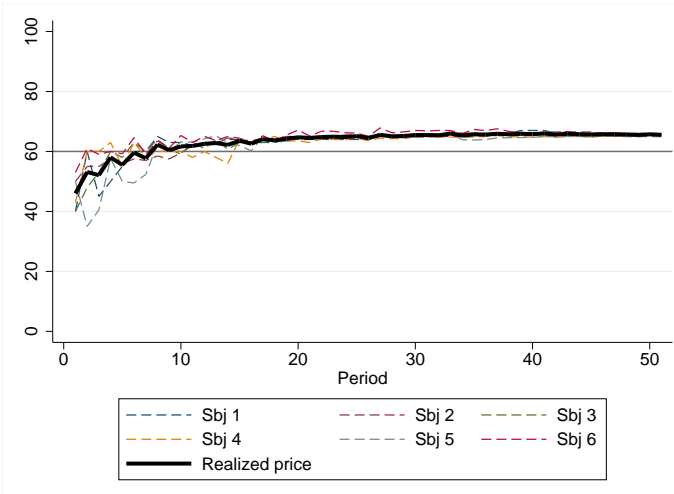

(e) Group 3

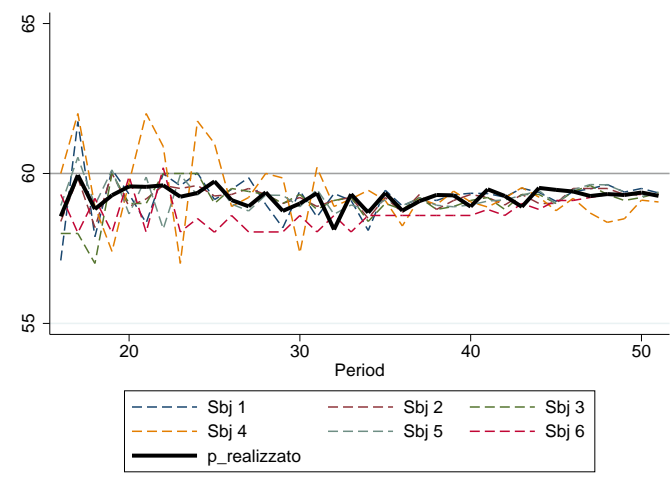

(b) Group 1

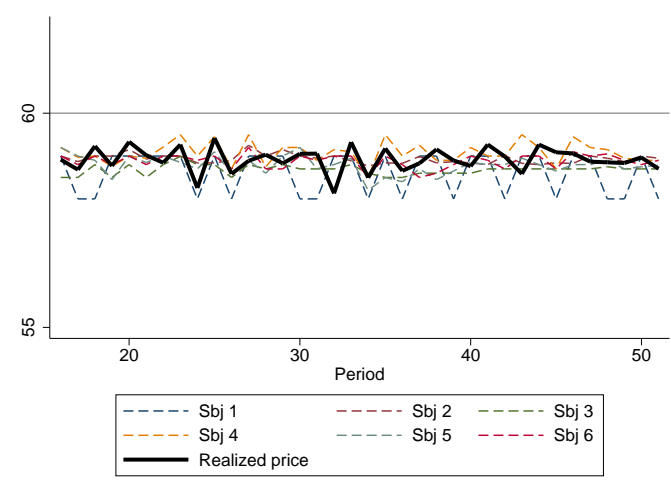

(d) Group 2

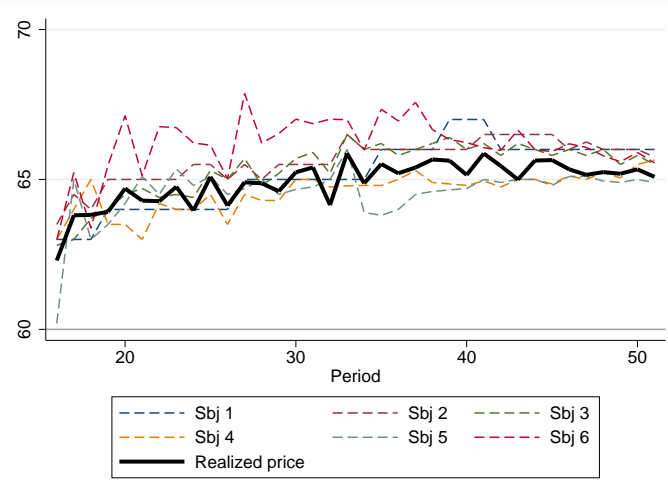

(f) Group 3

Figure 2: Individual prediction and fundamental price for each group (Treatment 1) 


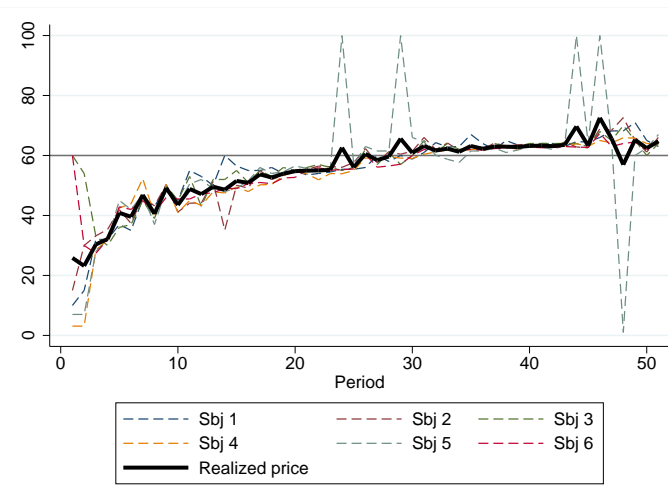

(a) Group 4

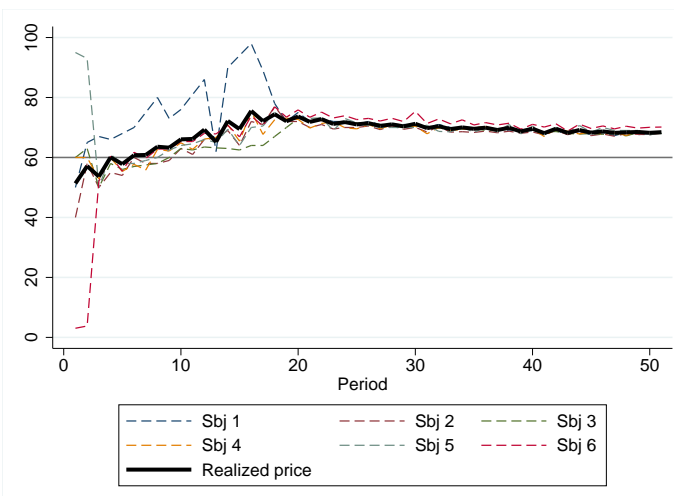

(c) Group 5

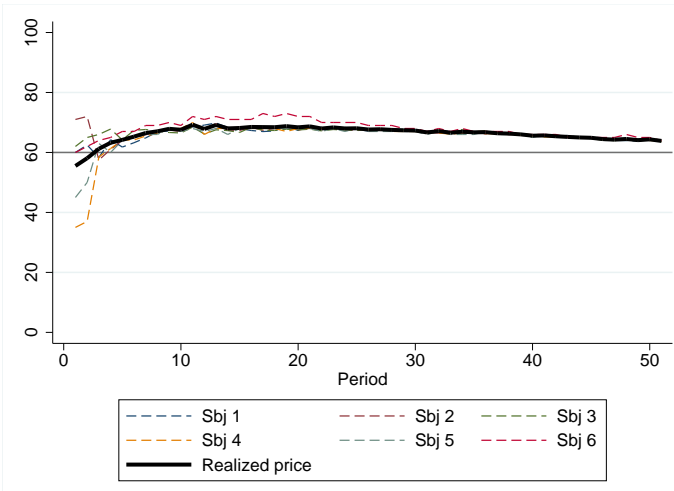

(e) Group 6

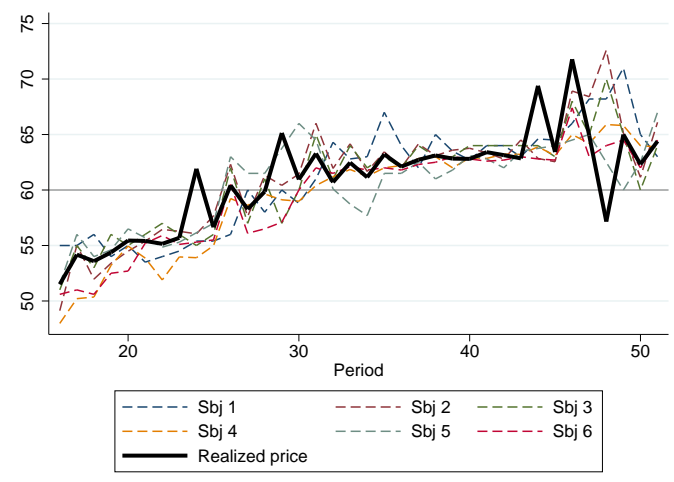

(b) Group 4

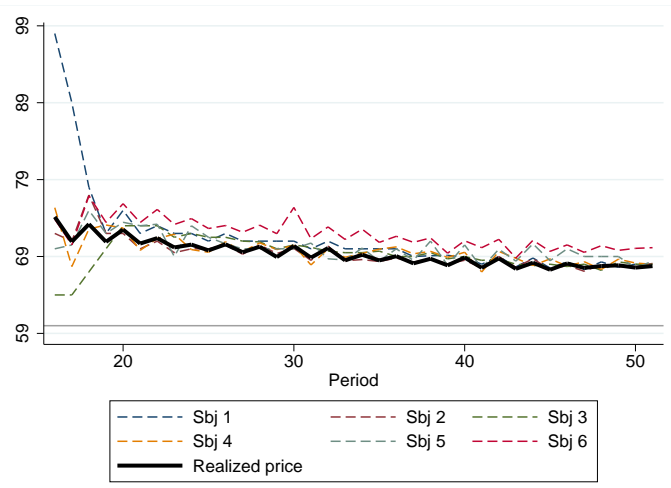

(d) Group 5

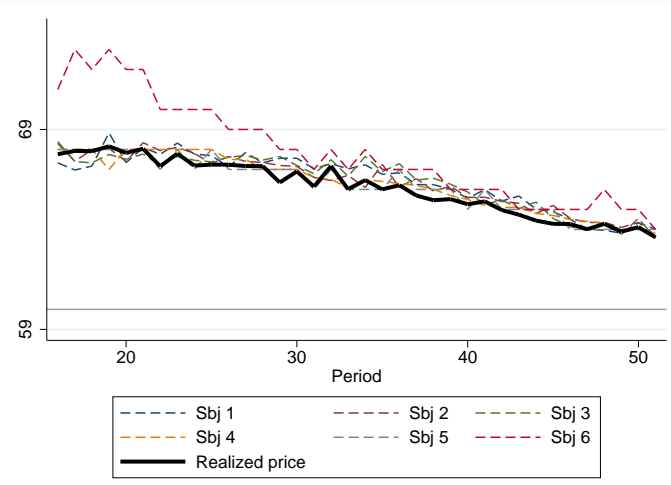

(f) Group 6

Figure 3: Individual prediction and fundamental price for each group (Treatment 1) 


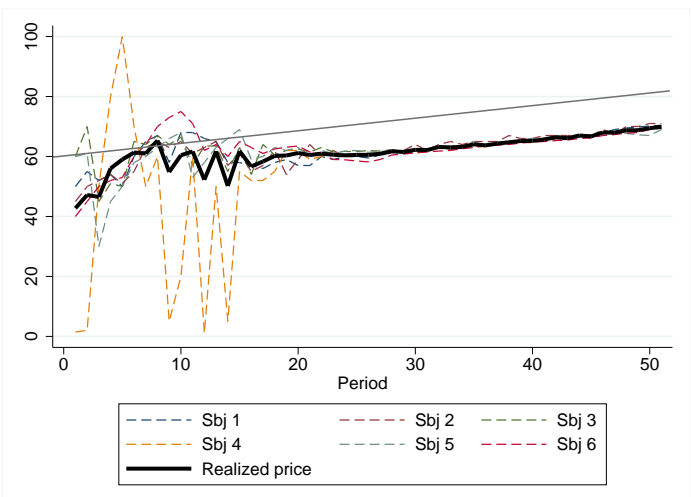

(a) Group 1

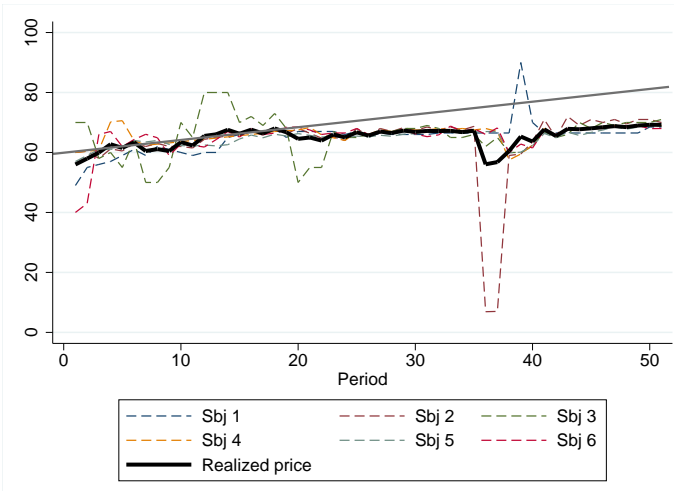

(c) Group 2

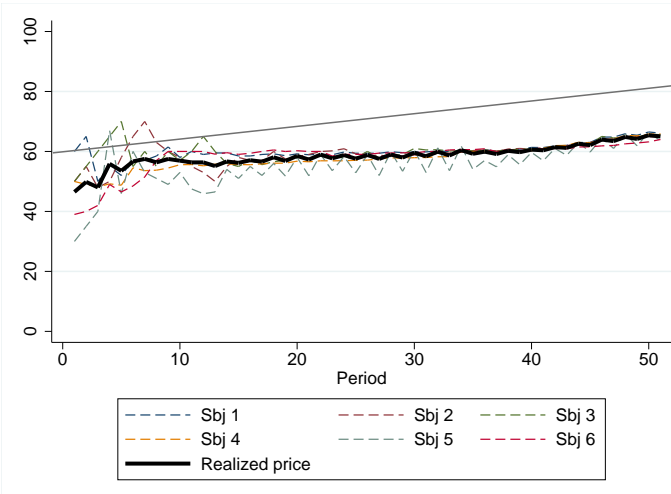

(e) Group 3

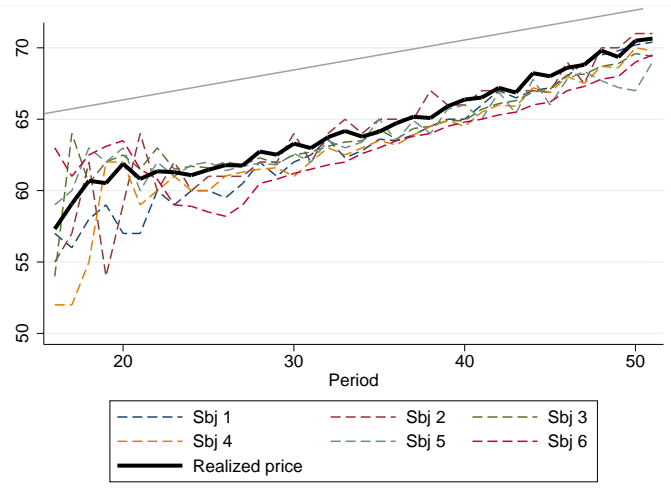

(b) Group 1

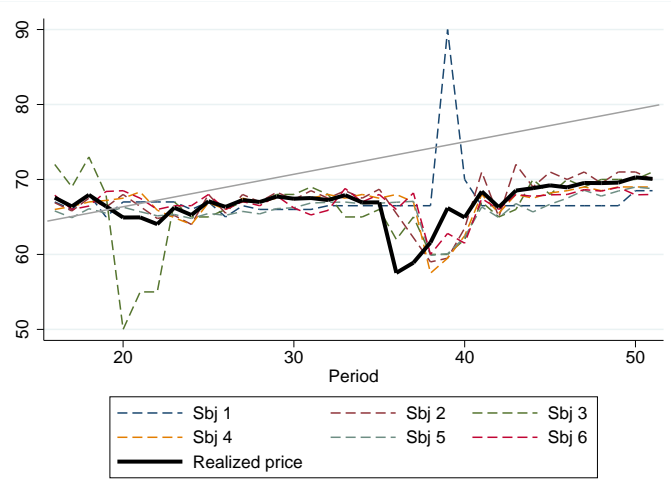

(d) Group 2

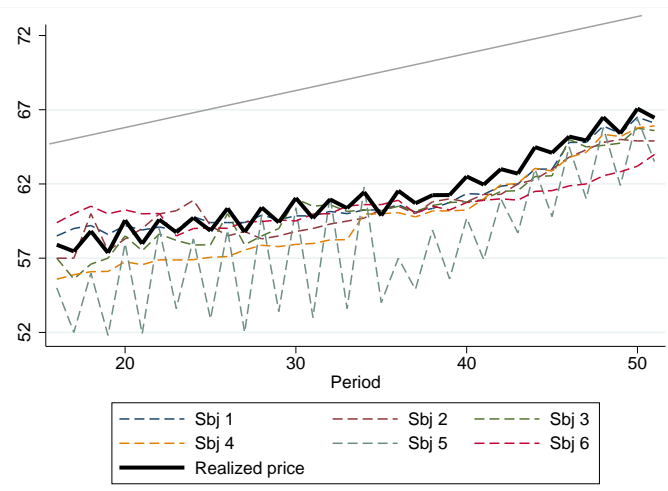

(f) Group 3

Figure 4: Individual prediction and fundamental price for each group (Treatment 2) 


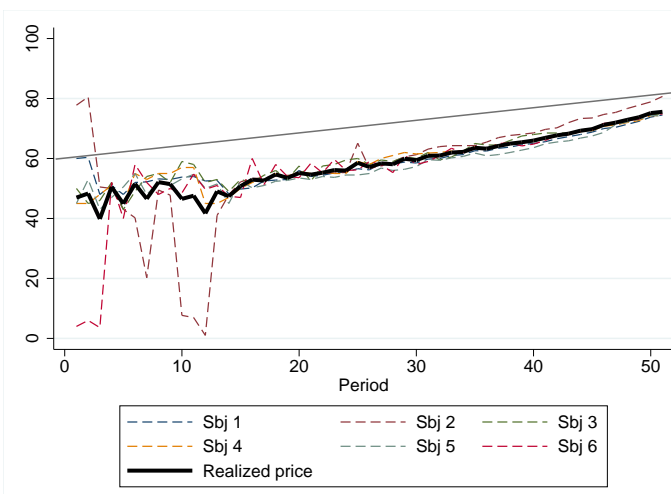

(a) Group 4

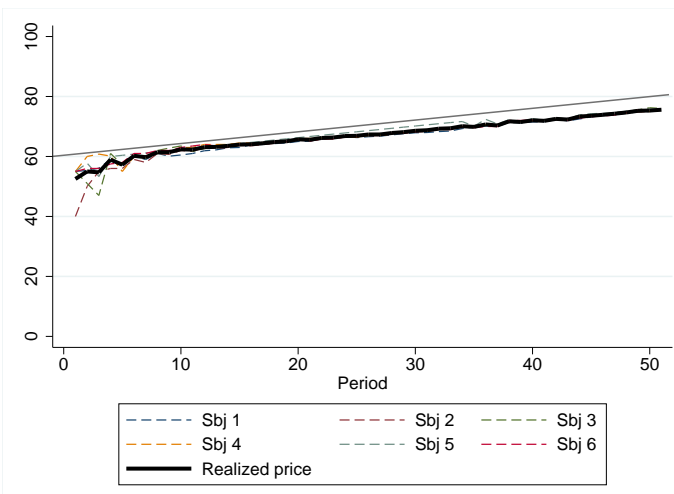

(c) Group 5

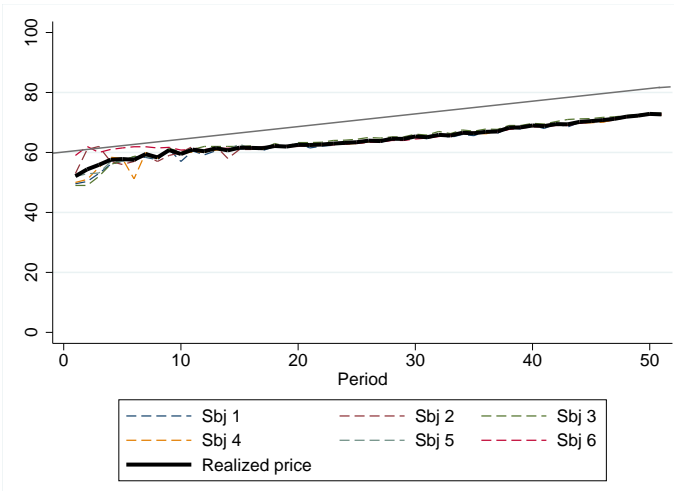

(e) Group 6

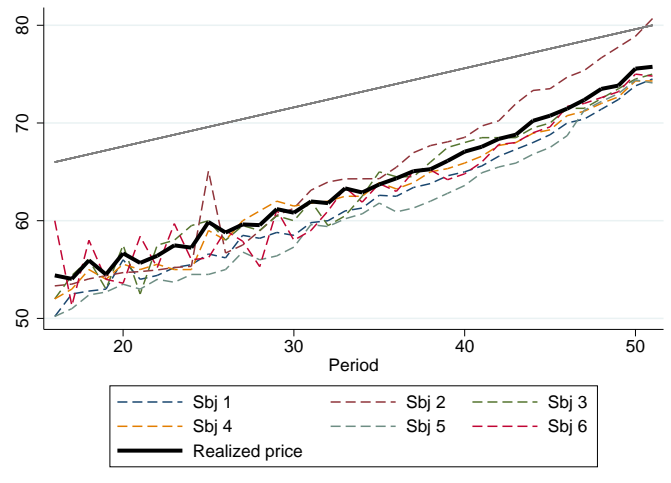

(b) Group 4

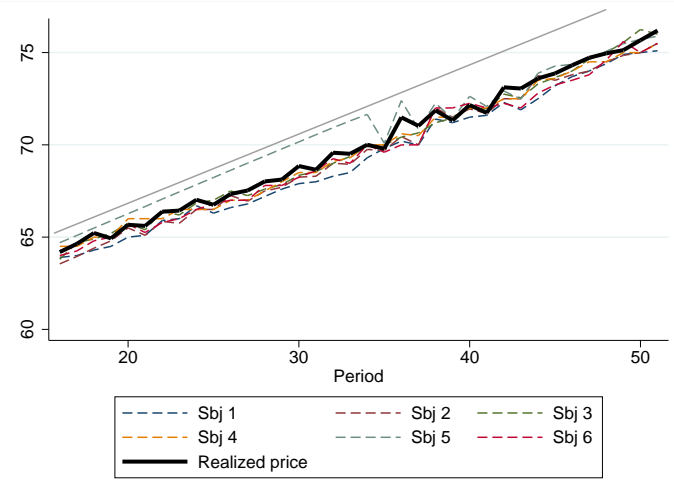

(d) Group 5

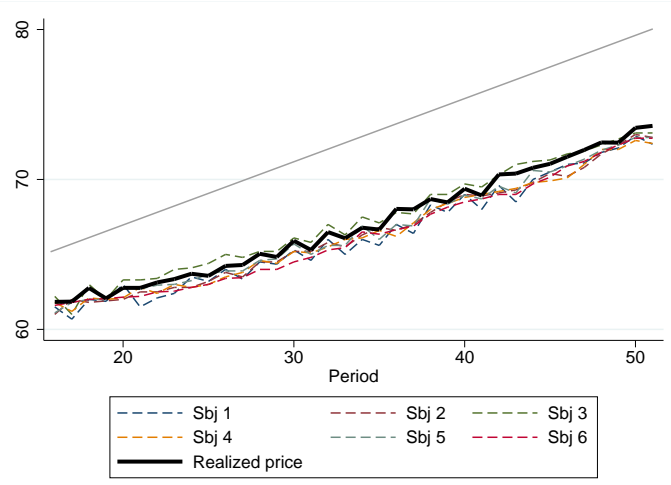

(f) Group 6

Figure 5: Individual prediction and fundamental price for each group (Treatment 2) 
the learning phase, i.e. even after the twentieth period. Despite these anomalous predictions, it seems that there is a good level of coordination. These results are similar to the main finding in Heemeijer et al. (2009) in which they compare the behavior in two different contexts: negative and positive feedback system. They find out that in the negative feedback system there is a fast convergence to the rational equilibrium but poor coordination. On the other hand, positive feedback system shows strong coordination and lack of convergence to the fundamental value.

From the graphical inspection a certain degree of heterogeneity both within and between groups emerges. According with Yalçın (2010), one of the assumptions of the Efficient Market Hypothesis (Fama (1970)) is that agents have rational expectations and they are able to predict the fundamental price. Our results show the failure of convergence to the fundamental price and different individuals' prediction strategies. There are two possible explanations for these results. First, in our setting, there is a positive feedback system and this means that individual strategies are strategic complements, i.e. if player $i$ increases her own prediction, player $j$ has an incentive to follow the same strategy (Bulow et al. (1985), Camerer and Fehr (2006)). Second, we consider a payoff function that depends on the realised price instead of on the fundamental price.

As Haltiwanger and Waldman (1985) and Haltiwanger and Waldman (1989) pointed out, players have different capabilities to form expectations. Indeed, some players, "the sophisticated agents", are able to compute the fundamental value, while other players use rules of thumb to make their predictions. In a context characterised by strategic complimentarity, the share of rational agents are crowed out by the bounded rational agents. This means that agents who have the capability of computing the fundamental price adjust their behaviour to maximize their profits and there is no incentive for rational players to predict the fundamental value when the others are moving away from it. Fehr and Tyran (2008) experimentally tested the different behavior in the case of strategic complements and substitutes. Their results show that there is a slow adjustment, or inertia, in the case of strategic complementarity while a quick convergence in the context of strategic substitutes. Similar conclusion are shown in Hommes et al. (2014). This confirms that complementarity leads to an irrational behaviour due to the incentive to follow the crowd.

Two key features emerge from this inspection. First, there is strong coordination among players despite the absence of any form of communication ${ }^{13}$. We

\footnotetext{
${ }^{13}$ For the sake of completeness we run a Wilcoxon test for each individual series in order to compare the difference between each pair of agents and the difference between individual predictions and the realized price. Results are shown in Appendix B.
} 
analyse in detail this aspect in the next section. Second, players face the same situation and start the game with the same information but reach a very different equilibrium. This means that the common knowledge of the dividend, the interest rate and the market price is not a sufficient condition to induce the same expectation among agents and, hence, there is heterogeneity both within and between groups.

\section{Individual versus aggregate expectations}

In the early 1900s, Galton (1907) observed two phenomena emerging from a competition. The first observation concerns the concept called The Wisdom of Crowd, in which the median of the collective forecast is equal to the realised value. This is the cornerstone of the REH proposed by Muth (1961). Even though he does not refer directly to Galton's work, Muth formalised the idea that heterogeneous uncorrelated expectations may be represented by aggregated expectations with bias on average equal to zero. The second observation is that the distribution of the forecast is skewed with respect to the median.

Lucas Jr and Prescott (1971) provides the definition of Individual Rational Expectation which is quite different from collective rational expectations. According to Lucas Jr and Prescott (1971), each agent is able to predict the future value of a variable without systematic errors because he/she takes into account all of the feasible information at time $t$, i.e.

$$
p_{t+1}^{e}=E\left(p_{t+1} \mid \Omega_{t}\right)=E_{t} p_{t+1}
$$

where $\Omega_{t}$ is the information set. The key feature of this approach is that the expected value of future forecasting error is equal to zero:

$$
E_{t}\left(p_{t+1}-E_{t} p_{t+1}\right)=0
$$

Figure 6 shows the comparison of the probability distribution of the realized price and the predicted price in each treatment, and Figure 7 shows the same relation between the realized price and the average price of groups. The $q$ - $q$ plot is a useful tool to compare the distributions of two variables. If the two distributions being compared are similar, the points in the plots will approximately lie on the bisector. It easy to see that in the case of individual predictions (Figure 6) the plot highlights a linear relation between the variables, but the points are not perfectly aligned on the bisector, in particular in Treatment 1. On the other hand, in the distribution of the average predictions is close to that of the realised price, especially concerning Treatment 2 .

As we noted, it is important to consider individual rationality, as suggested by Lucas Jr and Prescott (1971), or the concept of collective rationality, which is the 


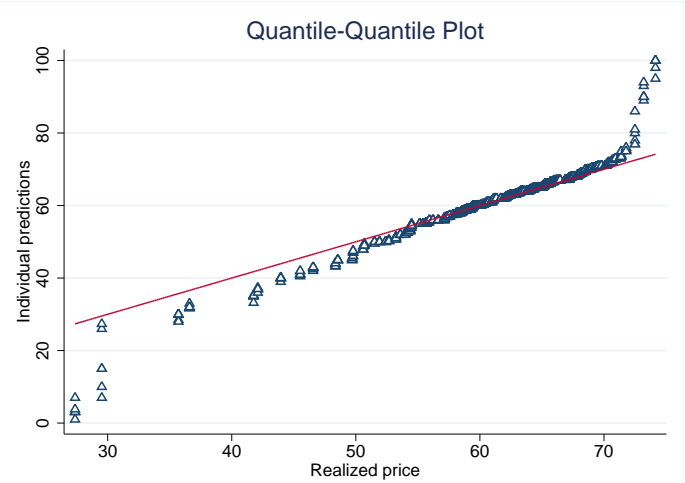

(a) Treatment 1

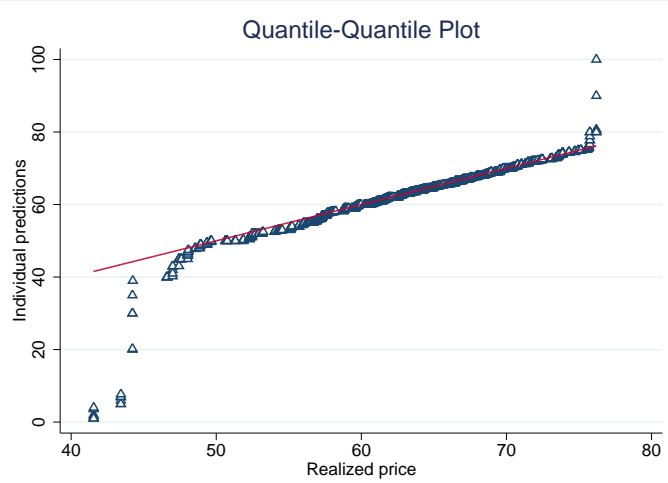

(b) Treatment 2

Figure 6: Quantile plot of the individual price by treatment

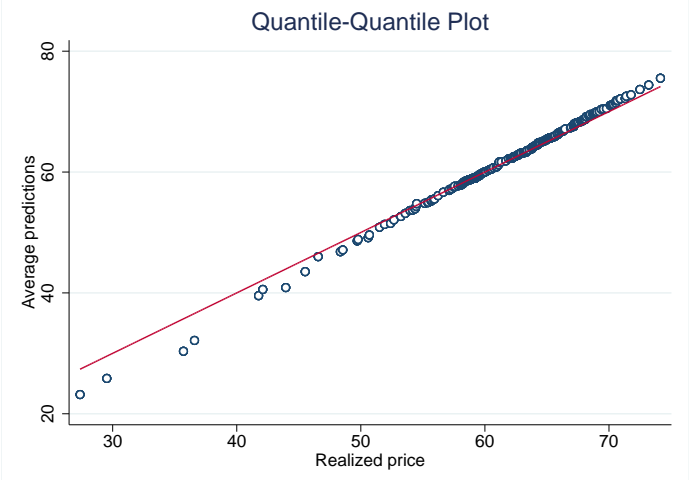

(a) Treatment 1

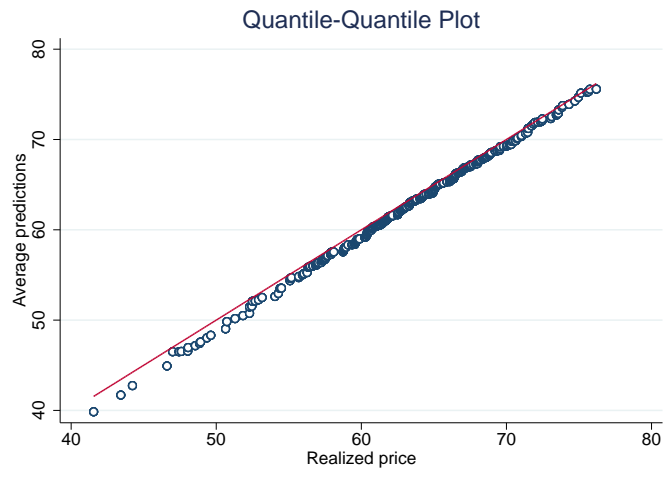

(b) Treatment 2

Figure 7: Quantile plot of the average price by treatment 
foundation of Galton's conjecture. The former suggested that each agent can overestimate or underestimate the objective variable, in our case the market price, but the average of the individual forecasting error should be equal to zero. Conversely, the latter concept suggests that each individual makes systematic forecasting errors but, if we consider the average aggregate predictions, we are able to obtain unbiased forecasts. We compute the average of the individual forecasting error and the average forecasting errors of the group by using the following equations:

$$
\begin{gathered}
\text { Individual error: } \quad \Xi_{i}=\frac{1}{T} \sum_{t=1}^{T}\left(p_{i t}^{e}-p_{t}\right)^{2} \\
\text { Aggregate error: } \quad \Xi_{j}=\frac{1}{n T} \sum_{t=1}^{T} \sum_{i=1}^{n}\left(p_{i t}^{e}-p_{t}\right)^{2}
\end{gathered}
$$

with $T=51$ and $n=6$. The analysis at the individual level is useful to test the hypothesis of individual rationality while the aggregate measure can be used to test the Galton's hypothesis. The results are shown in Figure 8 and Figure 9 and

Looking at Figure 8, we observe that some agents overestimate and others underestimate the realised price, but the mean value for each player is different from zero. This result discards the hypothesis of individual rationality. In Figure 9 , we show the difference between the average group forecast and the realized price. It is easy to see that these errors are close to zero. We therefore test whether the average errors with respect to the realised price are statistically different from zero, running a t-test and a Wilcoxon test. The results are shown in Table 2. The test result highlights that the mean Treatment 1 is equal to zero, while the mean in Treatment 2 is significantly negative. Kirman (1993), in fact, suggests that it is an oversimplification to look only at the individual behaviour and that we should consider the aggregate outcome that emerges from the agents' interactions. Moreover, Kirman (2010) and Chen and Yeh (2002) highlight that the rational equilibrium can be seen as an emergent property of a system with interactive bounded rational agents.

We can conclude that, in our sample, the Lucas concept of rationality is not verified. Moreover, the concept of collective rationality is true only in the case in which the variable to be estimated is constant over time, while there is also a bias at the aggregate level if the value to be estimated changes over time.

As suggested in Kirman (2014), in some situations it is rational to not be fully rational. In our context this results in a situation in which it is more convenient to "follow the crowd" than to predict the fundamental price. This means that each agent tries to understand the expectations of other players and seeks to coordinate to obtain more profits. We analyse the level of coordination in each group by 


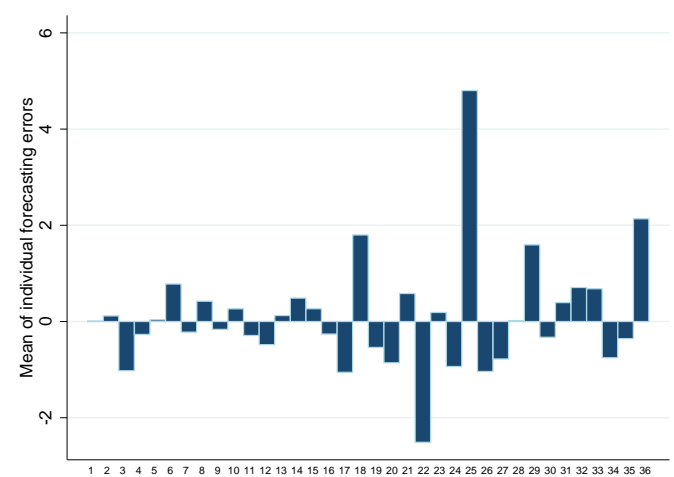

(a) Treatment 1

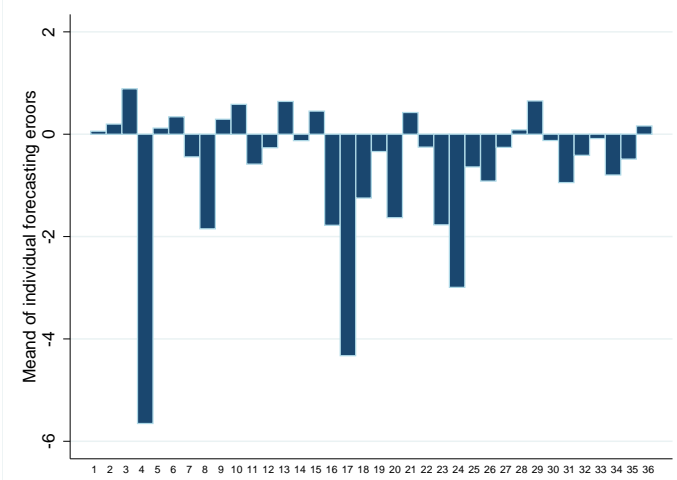

(b) Treatment 2

Figure 8: Average of the forecasting errors computed for each subject by using eq. (17).

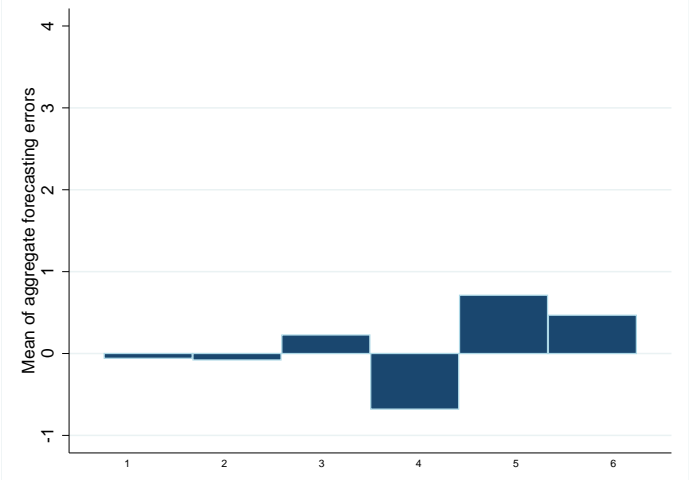

(a) Treatment 1

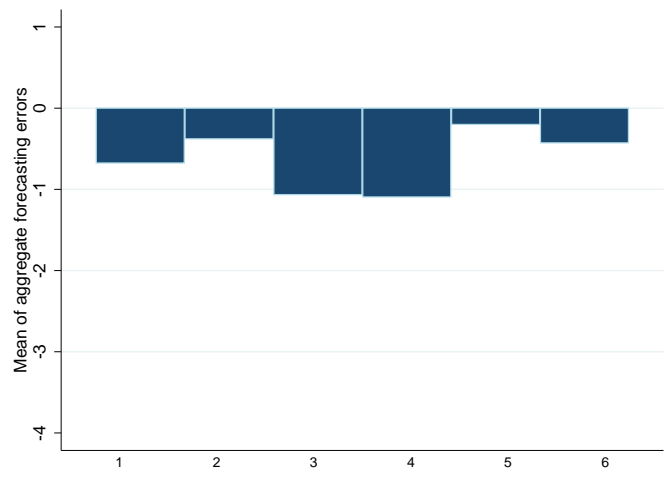

(b) Treatment 2

Figure 9: Average of the aggregate forecasting errors computed for each group by using eq. (18).

Table 2: Average forecasting errors with respect to the realized price (t-test and Wilcoxon test).

\begin{tabular}{lccccc}
\hline & \multicolumn{2}{c}{ t-test } & \multicolumn{2}{c}{ Wilcoxon } \\
\hline & Mean & t & p-value & z & p-value \\
\hline Treatment 1 & 0.098 & 0.9110 & 0.36 & 3.833 & $<0.01$ \\
Treatment 2 & -0.640 & -5.177 & $<0.01$ & -13.000 & $<0.01$ \\
\hline
\end{tabular}




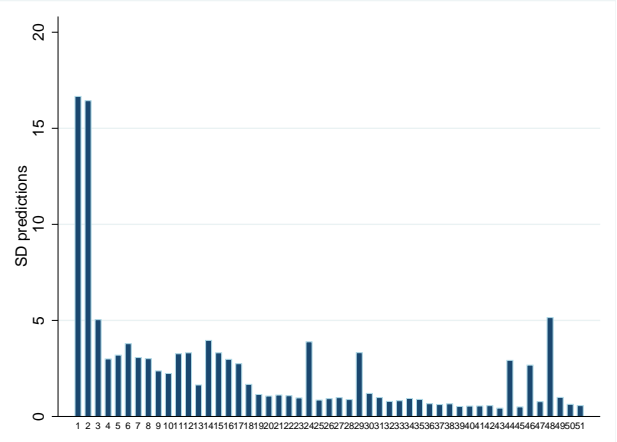

(a) Treatment 1

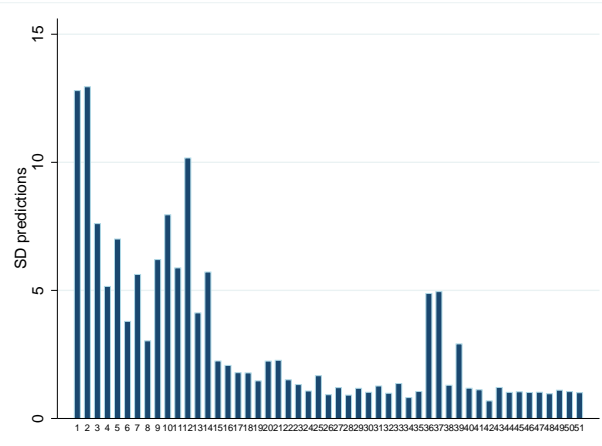

(b) Treatment 2

Figure 10: Average of the standard deviation of individual prediction for each period.

Table 3: Mean and standard errors of forecasts in Treatment 1

\begin{tabular}{|c|c|c|c|c|c|c|c|c|c|c|}
\hline Groups & Average 1-10 & Std.Dev. & Average 11-20 & Std.Dev. & Average 21-30 & Std.Dev. & Average $31-40$ & Std.Dev. & Average 41-51 & Std.Dev. \\
\hline 1 & 58.31 & 9.35 & 59.02 & 1.66 & 59.25 & 0.91 & 58.93 & 0.38 & 59.19 & 0.28 \\
\hline 2 & 57.80 & 3.42 & 58.83 & 0.46 & 58.89 & 0.29 & 58.76 & 0.31 & 58.83 & 0.29 \\
\hline 3 & 56.65 & 6.88 & 63.23 & 1.87 & 64.99 & 0.88 & 65.67 & 0.88 & 65.72 & 0.57 \\
\hline 4 & 37.19 & 12.92 & 51.16 & 4.24 & 58.89 & 8.19 & 62.57 & 1.54 & 64.57 & 10.81 \\
\hline 5 & 59.44 & 13.81 & 71.01 & 7.81 & 71.33 & 1.45 & 69.65 & 1.11 & 65.53 & 1.06 \\
\hline 6 & 63.65 & 6.84 & 68.50 & 1.69 & 67.87 & 0.94 & 66.51 & 0.61 & 64.79 & 0.62 \\
\hline
\end{tabular}

looking at the volatility of predictions made during the repetitions, with an eye to investigating the process of individual learning. As stressed in the previous Section, the level of coordination is good in almost all of the groups. In order to have a quantitative measure of this coordination, we use as a proxy the standard deviation of individual predictions. First of all we compute the average variance of individual predictions in both treatments. Figures 10 shows the evolution over time of this variable. It is easy to see that there is a strong reduction in volatility, especially in Treatment 1. Moreover, we split the entire series of 51 periods in different subsamples of ten periods and then computed the mean and the standard deviation of subjects' predictions in order to analyse whether there was a convergence through the fundamental value and to examine the volatility of the process. The results are shown in Table 3 and Table 4.

Table 4: Mean and standard errors of forecasts in Treatment 2

\begin{tabular}{lcccccccccc}
\hline Groups & Average 1-10 & Std.Dev. & Average 11-20 & Std.Dev. & Average 21-30 & Std.Dev. & Average 31-40 & Std.Dev. & Average 41-51 & Std.Dev. \\
\hline 1 & 55.43 & 16.91 & 58.44 & 11.25 & 60.98 & 1.34 & 63.87 & 1.19 & 67.48 \\
2 & 60.71 & 5.77 & 66.09 & 4.59 & 66.00 & 2.32 & 63.78 & 11.53 & 68.08 \\
3 & 53.88 & 7.95 & 56.78 & 1.98 & 58.32 & 1.98 & 59.62 & 1.85 & 62.96 \\
4 & 47.88 & 13.95 & 50.54 & 9.41 & 57.35 & 2.57 & 63.34 & 2.33 & 70.69 \\
5 & 58.36 & 4.17 & 64.02 & 1.24 & 67.10 & 1.09 & 70.37 & 1.23 & 73.70 \\
6 & 57.33 & 3.72 & 61.47 & 0.91 & 63.96 & 1.00 & 66.90 & 1.30 & 70.74 \\
\hline
\end{tabular}


First, the volatility is higher in the second Treatment, which is due to the variability of the fundamental value. Except for a few groups, i.e. Group 4 in Treatment 1 and Group 2 in Treatment $2^{14}$, we can observe a strong reduction in the volatility from the starting period to the end of the game, in line with the results shown in Figure 10. This means that players coordinate on a common strategy after, at least, 10 periods. This analysis confirms Galton's assertion regarding the accuracy of aggregate predictions over the individual ones.

\section{Is there evidence for the correction bias?}

As mentioned in the previous section, we can consider the individual rationality or the collective one. In general, the REH implies that agents, using all feasible information, are able to understand the real mechanism of the economy and are able to update and correct their forecasts. This implies that agents do not need a learning period or to adapt to new conditions; since they know the true behaviour of the market, their one step ahead forecasting error is on average zero. In our setting, since that the mean dividend and the interest rate are common knowledge, the rational expectations predictions should be:

$$
p_{i t}^{e}=p^{f}
$$

in each period. Within this framework, the possibility that a share of investors has imperfect information, or a lower "degree" of rationality, is ignored on the basis that they would be ruled out - via market selection - by "smart money" investors, and/or assuming that their impact on aggregate dynamics is negligible (Friedman, 1953; Lucas, 1978).

The analysis in the previous sections suggests that there is no evidence for rational expectations, either individually or collectively. Observing the graphical results, it seems that almost all agents do not use rational expectation to make their prediction, but they probably use some kind of adaptive expectation. Indeed, especially in Treatment 2, they systematically underestimate both the fundamental value and the realized price.

As pointed out, if players form their expectations using an adaptive scheme, they introduce a correction based on their own previous errors. As in equation (1), agents assign the weight $\lambda$ to their previous forecasting errors. This obviously implies that there is a correlation among individual forecasting errors. On the other hand, under the REH, since that the rationality condition holds, we should expect an absence of correlation.

\footnotetext{
${ }^{14}$ The standard deviation of the price is strongly influenced by the very high and low predictions of one player in the group.
} 
Table 5: Output Regression: Correlation of forecasting errors

\begin{tabular}{lcc}
\hline & Treatment 1 & Treatment 2 \\
\hline$\Xi_{i t-1}$ & $.359^{* * *}$ & $.508^{* * *}$ \\
& 0.000 & 0.000 \\
Constant & .077 & $-0.321^{* * *}$ \\
& .520 & .000 \\
\hline $\mathrm{N}$ & 1764 & 1764 \\
\hline$* p<0.05, * * p<0.01, * * * p<0.001$ & \\
\hline \hline
\end{tabular}

In order to test whether there is serial independence for the forecasting errors, we run the following regression:

$$
\Xi_{i t}=\beta_{0}+\beta_{1} \Xi_{i t-1}+\varepsilon_{i t}
$$

where $\Xi_{i t}$ is the difference between the predicted and the realised price for each agent, i.e., the individual forecasting error. Under the REH we should observe $\beta_{1}=0$. The estimation ${ }^{15}$ results for each treatment are shown in Table 5 .

The t ratio associated with the $\beta_{1}$ coefficients suggests that the REH is strongly rejected while there is evidence that players use an adaptive scheme.

Once established that expectations are adaptive, we were interested in the analysis of the error correction bias as described in Section 2.

First, we compute the absolute distance between the predicted price and the fundamental price in Treatment 2 and we compute a regression including only the period dummy $\left(\left|\Xi_{i t}\right|=\gamma_{0}+\gamma_{1}\right.$ Period $_{1}+\gamma_{2}$ Period $_{2}+\ldots+\gamma_{51}$ Period $_{51}+$ $\left.\varepsilon_{i t}\right)$. The results in Table 6 show that as the time increases the distance between individual predictions and the fundamental value decreases. This evidence suggests two aspects: first, it confirms that players take into account the fundamental value to form their expectations; second, in Treatment 2, this result supports the theory of error correction.

To better investigate the latter point, we make the assumption that agents use the simplest adaptive rule described by equation (20) and we estimate the following equation for Treatment $2^{16}$ :

\footnotetext{
${ }^{15}$ We run a dynamic panel estimation to take into account the problem with the lagged dependent variable.

${ }^{16}$ Since we are interested in understanding whether players are able to understand, and correct the trend, we only take into account data for Treatment 2.
} 
Table 6: Output Regression: Forecasting errors with respect to the fundamental price

\begin{tabular}{|c|c|c|c|}
\hline & Treatment 2 & & Treatment 2 \\
\hline Period 1 & $\begin{array}{c}0.000 \\
(.)\end{array}$ & Period 26 & $\begin{array}{c}-4.302 * * * \\
(1.509)\end{array}$ \\
\hline Period 2 & $\begin{array}{l}-1.188 \\
(1.509)\end{array}$ & Period 27 & $\begin{array}{c}-4.152^{* * *} \\
(1.509)\end{array}$ \\
\hline Period 3 & $\begin{array}{l}-1.726 \\
(1.509)\end{array}$ & Period 28 & $\begin{array}{c}-4.216^{* * *} \\
(1.509)\end{array}$ \\
\hline Period 4 & $\begin{array}{c}-5.405^{* * *} \\
(1.509)\end{array}$ & Period 29 & $\begin{array}{c}-4.093^{* * *} \\
(1.509)\end{array}$ \\
\hline Period 5 & $\begin{array}{c}-3.006^{* *} \\
(1.509)\end{array}$ & Period 30 & $\begin{array}{c}-4.140^{* * *} \\
(1.509)\end{array}$ \\
\hline Period 6 & $\begin{array}{c}-7.229^{* * *} \\
(1.509)\end{array}$ & Period 31 & $\begin{array}{c}-3.809^{* *} \\
(1.509)\end{array}$ \\
\hline Period 7 & $\begin{array}{c}-6.101^{* * *} \\
(1.509)\end{array}$ & Period 32 & $\begin{array}{c}-4.061^{* * *} \\
(1.509)\end{array}$ \\
\hline Period 8 & $\begin{array}{c}-7.188^{* * *} \\
(1.509)\end{array}$ & Period 33 & $\begin{array}{c}-3.597^{* *} \\
(1.509)\end{array}$ \\
\hline Period 9 & $\begin{array}{c}-5.879^{* * *} \\
(1.509)\end{array}$ & Period 34 & $\begin{array}{c}-3.755^{* *} \\
(1.509)\end{array}$ \\
\hline Period 10 & $\begin{array}{c}-4.958^{* * *} \\
(1.509)\end{array}$ & Period 35 & $\begin{array}{c}-3.538^{* *} \\
(1.509)\end{array}$ \\
\hline Period 11 & $\begin{array}{c}-5.934^{* * *} \\
(1.509)\end{array}$ & Period 36 & $\begin{array}{l}-1.495 \\
(1.509)\end{array}$ \\
\hline Period 12 & $\begin{array}{c}-3.239^{* *} \\
(1.509)\end{array}$ & Period 37 & $\begin{array}{l}-1.302 \\
(1.509)\end{array}$ \\
\hline Period 13 & $\begin{array}{c}-5.828^{* * *} \\
(1.509)\end{array}$ & Period 38 & $\begin{array}{l}-2.334 \\
(1.509)\end{array}$ \\
\hline Period 14 & $\begin{array}{c}-3.562^{* *} \\
(1.509)\end{array}$ & Period 39 & $\begin{array}{l}-1.973 \\
(1.509)\end{array}$ \\
\hline Period 15 & $\begin{array}{c}-6.083^{* * *} \\
(1.509)\end{array}$ & Period 40 & $\begin{array}{l}-2.550^{*} \\
(1.509)\end{array}$ \\
\hline Period 16 & $\begin{array}{c}-5.514^{* * *} \\
(1.509)\end{array}$ & Period 41 & $\begin{array}{c}-2.970^{* *} \\
(1.509)\end{array}$ \\
\hline Period 17 & $\begin{array}{c}-5.481^{* * *} \\
(1.509)\end{array}$ & Period 42 & $\begin{array}{l}-2.843^{*} \\
(1.509)\end{array}$ \\
\hline Period 18 & $\begin{array}{c}-6.131^{* * *} \\
(1.509)\end{array}$ & Period 43 & $\begin{array}{l}-2.801^{*} \\
(1.509)\end{array}$ \\
\hline Period 19 & $\begin{array}{c}-5.506^{* * *} \\
(1.509)\end{array}$ & Period 44 & $\begin{array}{c}-3.209^{* *} \\
(1.509)\end{array}$ \\
\hline Period 20 & $\begin{array}{c}-5.671^{* * *} \\
(1.509)\end{array}$ & Period 45 & $\begin{array}{l}-2.926^{*} \\
(1.509)\end{array}$ \\
\hline Period 21 & $\begin{array}{c}-4.971^{* *} \\
(1.509)\end{array}$ & Period 46 & $\begin{array}{c}-3.453^{* *} \\
(1.509)\end{array}$ \\
\hline Period 22 & $\begin{array}{c}-4.999^{* * *} \\
(1.509)\end{array}$ & Period 47 & $\begin{array}{c}-3.283^{* *} \\
(1.509)\end{array}$ \\
\hline Period 23 & $\begin{array}{c}-4.889^{* * *} \\
(1.509)\end{array}$ & Period 48 & $\begin{array}{c}-3.527^{* *} \\
(1.509)\end{array}$ \\
\hline Period 24 & $\begin{array}{c}-4.581^{* * *} \\
(1.509)\end{array}$ & Period 49 & $\begin{array}{c}-3.404^{* *} \\
(1.509)\end{array}$ \\
\hline \multirow[t]{2}{*}{ Period 25} & $\begin{array}{c}-4.756^{* * *} \\
(1.509)\end{array}$ & Period 50 & $\begin{array}{c}-3.717^{* *} \\
(1.509)\end{array}$ \\
\hline & & Period 51 & $\begin{array}{c}-3.354^{* *} \\
(1.509)\end{array}$ \\
\hline Constant & $\begin{array}{c}12.074^{* * *} \\
(1.067)\end{array}$ & & \\
\hline $\mathrm{R} 2$ & 0.057 & & \\
\hline $\mathrm{N}$ & 1836 & & \\
\hline
\end{tabular}


Table 7: Output Regression: Adaptive expectation estimation

\begin{tabular}{lc}
\hline & Treatment 2 \\
\hline$p_{i t}$ & $0.366^{* * *}$ \\
& $(0.057)$ \\
$p_{i t-1}$ & $0.647^{* * *}$ \\
& $(0.058)$ \\
$\left(p^{e}-p f\right)$ & $0.087^{*}$ \\
& $(0.045)$ \\
\hline $\mathrm{N}$ & 1476 \\
Sargan & $\chi_{11}^{2}=126.31$ \\
(p-value) & 0.000 \\
Hansen & $\chi_{11}^{2}=2.33$ \\
(p-value $)$ & 0.997 \\
AR(1) & $z=-1.74$ \\
(p-value) & 0.082 \\
\hline
\end{tabular}

Standard error in parentheses; $* p<0.05, * * p<0.01, * * * p<0.001$

$$
p_{i t+1}^{e}=\beta_{1} p_{i t}^{e}+\beta_{2} p_{i t-1}+\beta_{3}\left(p_{i t}^{e}-p f_{t}\right)+\varepsilon_{i t}
$$

using the Blundell and Bond estimator (Blundell and Bond (1998)). We consider the lagged values of the predicted price, the realised price and the fundamental value as instruments ${ }^{17}$.

The estimation results shown in Table 7 suggest that the model of the simple adaptive rule seems to fit well with the behaviour in our game; in fact, the coefficients $\beta_{1}$ and $\beta_{2}$ are strongly significant. Similar conclusions emerges in the analysis carried out in Heemeijer et al. (2009) where they estimate a similar regression for any subject. Also in that case, the predominant forecasting rule is the adaptive one.

Based on the theoretical assumption described in Section 2, in order to understand if a "correction bias" exists, we are especially interested in the value of the coefficient $\beta_{3}$. This coefficient turns out to be is small but significant. A positive and significant coefficient means that, as the distance between the predictions and

\footnotetext{
${ }^{17}$ Both the predicted and the realised series are stationary. We run the unit root test for panel with serial correlation (Pesaran (2007)). The results are $z=-6.229, p-$ value $=0.000$ for Treatment 1 and $z=-6.699, p-$ value $=0.000$ for Treatment 2. Consequently the null hypothesis of integration is strongly rejected.
} 
the fundamental price increases, subjects adjust their forecasts to fill the gap.

Mixing results from the descriptive statistics and from the econometric analysis, we can conclude that players are able to understand that there is an up-ward trend in the fundamental price but they systematically underestimate the trend. This supports the notion that there is some sort of correction in expectation formation but we are not able to prove that this error correction term fulfils the zero mean condition.

Furthermore, there is a good deal of heterogeneity between and within groups. Tables from 10 to 21 (Appendix B) show the pairwise Wilcoxon test within each group for the two treatments. In the lower triangular matrix there are the $\mathrm{z}$ statistics (and the p-values) comparing time series of expectations for each couple of agents, whereas the last two columns of every table show the z statistics (and the p-values) comparing the time series of expectations and the realised price for each agent. The tables show different behaviours among agents and different abilities to learn the realised price.

\section{Final Remarks}

In this work we investigate the individual behaviour in an experimental asset market in which participants play in groups of six. In this market players see in their screen the following information: $i$ ) the mean dividend, ii) the interest rate and iii) the past realisation of the market price and their own past predictions. The realised price is a function of the average forecasting of the group. We run two treatments in which the only difference is the process that generates the fundamental price: in Treatment 1 both the mean dividend and the interest rate are constant, while in Treatment 2 the mean dividend increases during repetitions.

By assuming that agents are myopic, the fundamental value is given by the ratio between the mean dividend and the interest rate. Under the rational expectation hypothesis, subjects are able to predict the fundamental price and, if this assumption holds, the realised price should converge to the fundamental one. Our results show that groups in both treatments seek to coordinate a price that is higher or lower than the fundamental one. In Treatment 2, in particular, players systematically underestimate the fundamental price, but are able to understand that the mean dividend follows an increasing trend.

The analysis in this paper is devoted to investigate two main features: 1) individual versus aggregate rationality; 2) the existence of a "correction bias" in individuals' predictions. First we investigate whether there is evidence for individual rationality. The results show that players fail to predict the fundamental value and that agents have adaptive expectations rather than rational ones. One of the main interesting results is the coordination among players, despite the absence of 
communication, which leads to the emergence of collective rationality. This concept refers to the process whereby agents learn the prediction strategies of others and they are able to coordinate on a price that is different from the fundamental value.

Since the experimental results suggest that players use adaptive expectation scheme, we analyze if, in a context in which the fundamental price follows a trend, the error correction mechanism (Palestrini and Gallegati (2015)) works. First of all, from the graphical analysis emerges that players are able to understand that the fundamental price follows an increasing linear trend, but agents systematically underestimate the magnitude of this trend. Estimation results confirm that players take into account the increasing fundamental price in making their forecasting. Thanks to these results we should conclude that there is a correction mechanism but it does not satisfy the zero mean condition, i.e. the rationality condition.

This work shows also different behaviours between agents and different ability to learn the realised price. The emergence of the heterogeneity both within and between groups and the rejection of the rational expectation hypothesis suggest that we need a model more sophisticated than the Neoclassical one. The next step is to extrapolate the individual prediction strategy using individual estimation and understand the mechanism of coordination that brought to the observed aggregate result.

\section{Acknowledgement - Funding}

This research has received funding from the European Union, Seventh Framework Programme under grant agreements n. SYMPHONY- ICT-2013-611875. 
Anufriev, M. and Hommes, C. (2012). Evolutionary selection of individual expectations and aggregate outcomes in asset pricing experiments. American Economic Journal: Microeconomics, 4(4), 35-64.

Assenza, T., Bao, T., Hommes, C., and Massaro, D. (2014). Experiments on expectations in macroeconomics and finance. In Experiments in macroeconomics, pages 11-70. Emerald Group Publishing Limited.

Babillot, M., Bougerol, P., Elie, L., et al. (1997). The random difference equation $x \backslash s b n=a \backslash \operatorname{sbn} x \backslash s b\{n-1\}+b \backslash s b n$ in the critical case. The Annals of Probability, 25(1), 478-493.

Bao, T., Hommes, C., Sonnemans, J., and Tuinstra, J. (2012). Individual expectations, limited rationality and aggregate outcomes. Journal of Economic Dynamics and Control, 36(8), 1101-1120.

Bao, T., Duffy, J., and Hommes, C. (2013). Learning, forecasting and optimizing: An experimental study. European Economic Review, 61, 186-204.

Bao, T., Hommes, C., Makarewicz, T., et al. (2014). Bubble formation and (in) efficient markets in learning-to-forecast and-optimize experiments. CeNDEF Working Paper.

Bhattacharya, R. and Majumdar, M. (2007). Random dynamical systems: theory and applications. Cambridge University Press.

Blanchard, O. J. and Kahn, C. M. (1980). The solution of linear difference models under rational expectations. Econometrica: Journal of the Econometric Society, pages $1305-1311$.

Bloomfield, R. and Hales, J. (2002). Predicting the next step of a random walk: experimental evidence of regime-shifting beliefs. Journal of financial Economics, 65(3), 397-414.

Blundell, R. and Bond, S. (1998). Initial conditions and moment restrictions in dynamic panel data models. Journal of econometrics, 87(1), 115-143.

Bottazzi, G., Devetag, G., and Pancotto, F. (2011). Does volatility matter? expectations of price return and variability in an asset pricing experiment. Journal of Economic Behavior 63 Organization, 77(2), 124-146.

Branch, W. A. (2004). The theory of rationally heterogeneous expectations: Evidence from survey data on inflation expectations*. The Economic Journal, 114(497), 592-621. 
Brock, W. A. and Hommes, C. H. (1998). Heterogeneous beliefs and routes to chaos in a simple asset pricing model. Journal of Economic dynamics and Control, 22(8-9), 1235-1274.

Bulow, J. I., Geanakoplos, J. D., and Klemperer, P. D. (1985). Multimarket oligopoly: Strategic substitutes and complements. The Journal of Political Economy, pages 488-511.

Camerer, C. F. and Fehr, E. (2006). When does "economic man" dominate social behavior? Science, 311(5757), 47-52.

Campbell, J. Y., Lo, A. W.-C., MacKinlay, A. C., et al. (1997). The econometrics of financial markets, volume 2. princeton University press Princeton, NJ.

Chen, S.-H. and Yeh, C.-H. (2002). On the emergent properties of artificial stock markets: the efficient market hypothesis and the rational expectations hypothesis. Journal of Economic Behavior \& Organization, 49(2), 217-239.

Chow, G. C. (2011). Usefulness of adaptive and rational expectations in economics. Center for Economic Policy Studies, Princeton University.

Duffy, J. (2010). Experimental macroeconomics. In Behavioural and Experimental Economics, pages 113-119. Springer.

Dufwenberg, M., Lindqvist, T., and Moore, E. (2005). Bubbles and experience: An experiment. American Economic Review, pages 1731-1737.

Dwyer, G. P., Williams, A. W., Battalio, R. C., and Mason, T. I. (1993). Tests of rational expectations in a stark setting. The Economic Journal, pages 586-601.

Evans, G. W. and Honkapohja, S. (2001). Learning and expectations in macroeconomics. Princeton University Press.

Fama, E. F. (1970). Efficient capital markets: A review of theory and empirical work*. The Journal of Finance, 25(2), 383-417.

Fehr, E. and Tyran, J.-R. (2008). Limited rationality and strategic interaction: the impact of the strategic environment on nominal inertia. Econometrica, 76(2), 353-394.

Fischbacher, U. (2007). z-tree: Zurich toolbox for ready-made economic experiments. Experimental Economics, 10(2).

Galton, F. (1907). Vox populi. Nature, pages 450-451. 
Grunberg, E. and Modigliani, F. (1954). The predictability of social events. The Journal of Political Economy, pages 465-478.

Haltiwanger, J. and Waldman, M. (1985). Rational expectations and the limits of rationality: An analysis of heterogeneity. The American Economic Review, pages $326-340$.

Haltiwanger, J. and Waldman, M. (1989). Limited rationality and strategic complements: the implications for macroeconomics. The Quarterly Journal of Economics, pages 463-483.

Heemeijer, P., Hommes, C., Sonnemans, J., and Tuinstra, J. (2009). Price stability and volatility in markets with positive and negative expectations feedback: An experimental investigation. Journal of Economic dynamics and control, 33(5), 1052-1072.

Hey, J. D. (1994). Expectations formation: Rational or adaptive or...? Journal of Economic Behavior \&5 Organization, 25(3), 329-349.

Hommes, C. (2011). The heterogeneous expectations hypothesis: Some evidence from the lab. Journal of Economic Dynamics and Control, 35(1), 1-24.

Hommes, C. (2013). Behavioral rationality and heterogeneous expectations in complex economic systems. Cambridge University Press.

Hommes, C., Sonnemans, J., Tuinstra, J., and Van de Velden, H. (2005). Coordination of expectations in asset pricing experiments. Review of Financial Studies, 18(3), 955-980.

Hommes, C., Sonnemans, J., Tuinstra, J., and Van De Velden, H. (2007). Learning in cobweb experiments. Macroeconomic Dynamics, 11(S1), 8-33.

Hommes, C., Sonnemans, J., Tuinstra, J., and van de Velden, H. (2008). Expectations and bubbles in asset pricing experiments. Journal of Economic Behavior \& Organization, 67(1), 116-133.

Hommes, C. H. (2014). Behaviorally rational expectations and almost self-fulfilling equilibria. Review of Behavioral Economics, 1(1-2), 75-97.

Hommes, C. H. et al. (2014). Behaviorally rational expectations and almost selffulfilling equilibria. Review of Behavioral Economics, 1(1-2), 75-97.

Kirchler, M. (2009). Underreaction to fundamental information and asymmetry in mispricing between bullish and bearish markets. an experimental study. Journal of Economic Dynamics and Control, 33(2), 491-506. 
Kirman, A. (1993). Ants, rationality, and recruitment. The Quarterly Journal of Economics, pages 137-156.

Kirman, A. (2010). Complex economics: individual and collective rationality. Routledge.

Kirman, A. (2014). Is it rational to have rational expectations? Mind 8 Society, 13(1), 29-48.

Lucas Jr, R. E. and Prescott, E. C. (1971). Investment under uncertainty. Econometrica: Journal of the Econometric Society, pages 659-681.

Marimon, R., Spear, S. E., and Sunder, S. (1993). Expectationally driven market volatility: an experimental study. Journal of Economic Theory, 61(1), 74-103.

Muth, J. F. (1961). Rational expectations and the theory of price movements. Econometrica: Journal of the Econometric Society, pages 315-335.

Nerlove, M. (1958). Adaptive expectations and cobweb phenomena. The Quarterly Journal of Economics, pages 227-240.

Noussair, C., Robin, S., and Ruffieux, B. (2001). Price bubbles in laboratory asset markets with constant fundamental values. Experimental Economics, 4(1), 87105.

Noussair, C. N. and Powell, O. (2010). Peaks and valleys: Price discovery in experimental asset markets with non-monotonic fundamentals. Journal of Economic Studies, 37(2), 152-180.

Palestrini, A. and Gallegati, M. (2015). Unbiased adaptive expectation schemes. Economics Bulletin, 35(2), 1185-1190.

Pesaran, M. H. (2007). A simple panel unit root test in the presence of cross-section dependence. Journal of Applied Econometrics, 22(2), 265-312.

Sargent, T. J. (1993). Bounded rationality in macroeconomics: The arne ryde memorial lectures. OUP Catalogue.

Smith, V. L., Suchanek, G. L., and Williams, A. W. (1988). Bubbles, crashes, and endogenous expectations in experimental spot asset markets. Econometrica: Journal of the Econometric Society, pages 1119-1151.

Yalçın, K. C. (2010). Market rationality: efficient market hypothesis versus market anomalies. European Journal of Economic and Political Studies, 3(2), 23-28. 


\section{AppendixA. General Instruction}

You are a financial advisor to a pension fund that is seeking to invest an amount of money to purchase an asset. The pension fund will allocate its money between a bank account that pays fixed interest and a risky investment. The allocation depends on the accuracy of your forecasts. Your task is to predict the price of the risky asset for 51 periods. Your profit depends on your forecast accuracy. The better your prediction, the higher the profit in each period. The final earning will be given by the sum of the profit you gain in each period.

\section{AppendixA.1. Instructions for the forecasting task}

At the beginning of each period you must predict the price for the next period, i.e. in period 1 you must predict the price of period 2 and so on. At the beginning of the experiment you should predict the price of the first and the second periods. Your forecasting for these periods must be between 0 and 100. To make these predictions, you will only have two pieces of information: the mean dividend and the interest rate. From period 3 until the end of the game you will have more information ${ }^{18}$ : besides the interest rate and the mean dividend, you will see a graph with the time series of your past predictions and the series of the realised price in the market. The green dots represent the series of the predicted price, while the blue dots represents the realised price in each period. Moreover, you will see the values of these series.

At period $t$ the feasible information will be: the realised prices up to period $t-2$, your past predictions up to period $t-1$ and your earnings up to period $t-2$.

Once each player has made his/her prediction for the first and the second period, the realised price in period 1 and your prediction in period 1 and period 2 will be revealed. The same mechanism holds for the subsequent periods. After you insert the forecasting your profit will be computed according to the forecasting accuracy. In each period your profit ranges between 0 (bad forecast) and 1 (best forecast). During the experiment your earning will be expressed in ECU (Experimental Currency Unit) and at the end of the game the amount will be converted into Euro (1 Euro = 4 ECU).

The market price will be determined by the equilibrium between the supply and demand of the stock. The supply of stock is fixed for the duration of the experiment. The demand for stock will be given by the aggregate demand of each pension fund for which each participant is the advisor.

\footnotetext{
${ }^{18}$ During the initial phase we gave a sheet to each player with the screenshot of the game with further information.
} 
AppendixA.2. Total profits

Table A.8 shows the total profit in Euro in each group. Table A.9 reports the descriptive statistics of the cash earned in both treatments.

Table A.8: Average payment by group

\begin{tabular}{ccc}
\hline & Treatment 1 & Treatment 2 \\
\hline Group 1 & 88.80 & 78.09 \\
Group 2 & 110.07 & 86.08 \\
Group 3 & 88.17 & 93.34 \\
Group 4 & 77.81 & 80.56 \\
Group 5 & 82.70 & 100.48 \\
Group 6 & 105.84 & 101.49 \\
\hline
\end{tabular}

Table A.9: Descriptive statistics of payment

\begin{tabular}{lcrrc}
\hline & Mean & Std. Dev & Min & Max \\
\hline Treatment 1 & 15.37 & 12.89 & 11.68 & 25.59 \\
Treatment 2 & 15.00 & 9.99 & 9.81 & 25.59 \\
\hline
\end{tabular}


AppendixB. Tables

Table B.10: Wilcoxon test for Group 1 - Treatment 1

\begin{tabular}{|c|c|c|c|c|c|c|c|c|c|c|c|c|c|c|}
\hline \multicolumn{15}{|c|}{ Group 1 - Treatment 1} \\
\hline Subject & $\mathrm{z}$ & $\mathrm{p}$-value & $\mathrm{z}$ & p-value & $\mathrm{z}$ & p-value & $\mathrm{z}$ & $\mathrm{p}$-value & $\mathrm{z}$ & p-value & $\mathrm{z}$ & $\mathrm{p}$-value & $\mathrm{z}$ & p-value \\
\hline 1 & & & & & & & & & & & & & 1.547 & 0.122 \\
\hline 2 & 1.611 & 0.107 & & & & & & & & & & & -0.366 & 0.715 \\
\hline 3 & 2.934 & 0.003 & 1.673 & 0.094 & & & & & & & & & -0.75 & 0.066 \\
\hline 4 & 2.252 & 0.024 & 1.263 & 0.207 & -0.255 & 0.799 & & & & & & & -1.837 & 0.4533 \\
\hline 5 & 1.211 & 0.226 & -0.017 & 0.9866 & -1.396 & 0.162 & -1.225 & 0.221 & & & & & 0.965 & 0.334 \\
\hline \multirow[t]{2}{*}{6} & 3.631 & 0.000 & 3.072 & 0.002 & 1.432 & 0.152 & 0.901 & 0.377 & 3.051 & 0.002 & & & -3.356 & 0.001 \\
\hline & \multicolumn{2}{|r|}{1} & \multicolumn{2}{|c|}{2} & \multicolumn{2}{|c|}{3} & \multicolumn{2}{|c|}{4} & \multicolumn{2}{|r|}{5} & & 6 & \multicolumn{2}{|c|}{ Realized price } \\
\hline
\end{tabular}

Table B.11: Wilcoxon test for Group 2 - Treatment 1

\begin{tabular}{|c|c|c|c|c|c|c|c|c|c|c|c|c|c|c|}
\hline \multicolumn{15}{|c|}{ Group 2 - Treatment 1} \\
\hline Subject & $\mathrm{z}$ & p-value & $\mathrm{z}$ & p-value & $\mathrm{z}$ & $\mathrm{p}$-value & $\mathrm{z}$ & $\mathrm{p}$-value & $\mathrm{z}$ & $\mathrm{p}$-value & $\mathrm{z}$ & p-value & $\mathrm{z}$ & $\mathrm{p}$-value \\
\hline 1 & & & & & & & & & & & & & -2.493 & 0.013 \\
\hline 2 & -2.238 & 0.025 & & & & & & & & & & & 2.222 & 0.026 \\
\hline 3 & 1.247 & 0.214 & 6.333 & 0.000 & & & & & & & & & -3.852 & 0.000 \\
\hline 4 & -3.485 & 0.001 & -1.351 & 0.177 & -6.029 & 0.000 & & & & & & & 3.449 & 0.001 \\
\hline 5 & 1.107 & 0.269 & 5.171 & 0 & -0.411 & 0.681 & 5.661 & 0.000 & & & & & -3.243 & 0.001 \\
\hline \multirow[t]{2}{*}{6} & -0.279 & 0.78 & 2.493 & 0.013 & -3.665 & 0.000 & 3.988 & 0.000 & -2.776 & 0.006 & & & -1.753 & 0.08 \\
\hline & \multicolumn{2}{|c|}{1} & \multicolumn{2}{|c|}{2} & \multicolumn{2}{|c|}{3} & \multicolumn{2}{|r|}{4} & \multicolumn{2}{|r|}{5} & & 6 & \multicolumn{2}{|c|}{ Realized price } \\
\hline
\end{tabular}


Table B.12: Wilcoxon test for Group 3 - Treatment 1

\begin{tabular}{|c|c|c|c|c|c|c|c|c|c|c|c|c|c|c|}
\hline \multicolumn{15}{|c|}{ Group 3 - Treatment 1} \\
\hline Subject & $\mathrm{z}$ & $\mathrm{p}$-value & $\mathrm{z}$ & p-value & $\mathrm{z}$ & $\mathrm{p}$-value & $\mathrm{z}$ & p-value & $\mathrm{z}$ & p-value & $\mathrm{z}$ & $\mathrm{p}$-value & $\mathrm{z}$ & $\mathrm{p}$-value \\
\hline 1 & & & & & & & & & & & & & 2.287 & 0.022 \\
\hline 2 & -0.907 & 0.645 & & & & & & & & & & & 3.759 & 0.000 \\
\hline 3 & -0.199 & 0.843 & 0.631 & 0.528 & & & & & & & & & 3.384 & 0.001 \\
\hline 4 & $1-995$ & 0.051 & 3.271 & 0.001 & 2.583 & 0.01 & & & & & & & -2.821 & 0.005 \\
\hline 5 & 1.6 & 0.11 & 3.254 & 0.001 & 2.274 & 0.023 & -0.308 & 0.758 & & & & & -2.025 & 0.043 \\
\hline \multirow[t]{2}{*}{6} & -2.864 & 0.004 & -2.375 & 0.018 & -2.845 & 0.004 & -4.928 & 0.000 & -4.77 & 0.000 & & & 6.168 & 0.000 \\
\hline & \multicolumn{2}{|c|}{1} & \multicolumn{2}{|c|}{2} & \multicolumn{2}{|c|}{3} & \multicolumn{2}{|r|}{4} & \multicolumn{2}{|r|}{5} & & 6 & \multicolumn{2}{|c|}{ Realized price } \\
\hline
\end{tabular}

Table B.13: Wilcoxon test for Group 4 - Treatment 1

\begin{tabular}{|c|c|c|c|c|c|c|c|c|c|c|c|c|c|c|}
\hline \multicolumn{15}{|c|}{ Group 4 - Treatment 1} \\
\hline Subject & $\mathrm{z}$ & $\mathrm{p}$-value & $\mathrm{z}$ & $\mathrm{p}$-value & $\mathrm{z}$ & $\mathrm{p}$-value & $\mathrm{z}$ & p-value & $\mathrm{z}$ & p-value & $\mathrm{z}$ & $\mathrm{p}$-value & $\mathrm{z}$ & $\mathrm{p}$-value \\
\hline 1 & & & & & & & & & & & & & -0.544 & 0.587 \\
\hline $\begin{array}{l}1 \\
2\end{array}$ & 0.281 & 0.779 & & & & & & & & & & & -1.322 & 0.186 \\
\hline 3 & 0.034 & 0.973 & -0.268 & 0.789 & & & & & & & & & -0.084 & 0.933 \\
\hline 4 & 1.272 & 0.204 & 0.716 & 0.474 & 1.272 & 0.203 & & & & & & & -4.265 & 0.000 \\
\hline 5 & 0.489 & 0.625 & 0.194 & 0.846 & 0.532 & 0.594 & -0.492 & 0.623 & & & & & -0.647 & 0.518 \\
\hline \multirow[t]{2}{*}{6} & 1.071 & 0.284 & 0.656 & 0.512 & 1.105 & 0.269 & -0.057 & 0.955 & 0.308 & 0.758 & & & -4.349 & 0.000 \\
\hline & \multicolumn{2}{|r|}{1} & \multicolumn{2}{|r|}{2} & \multicolumn{2}{|r|}{3} & \multicolumn{2}{|c|}{4} & \multicolumn{2}{|r|}{5} & & 6 & \multicolumn{2}{|c|}{ Realized price } \\
\hline
\end{tabular}

Table B.14: Wilcoxon test for Group 5 - Treatment 1

\begin{tabular}{|c|c|c|c|c|c|c|c|c|c|c|c|c|c|c|}
\hline \multicolumn{15}{|c|}{ Group 5 - Treatment 1} \\
\hline Subject & $\mathrm{z}$ & p-value & $\mathrm{z}$ & $\mathrm{p}$-value & $\mathrm{z}$ & $\mathrm{p}$-value & $\mathrm{z}$ & p-value & z & p-value & z & p-value & $\mathrm{z}$ & $\mathrm{p}$-value \\
\hline 1 & & & & & & & & & & & & & 5.486 & 0.000 \\
\hline 2 & 3.838 & 0.000 & & & & & & & & & & & -2.953 & 0.003 \\
\hline 3 & 3.779 & .000 & -0.097 & 0.923 & & & & & & & & & -0.609 & 0.542 \\
\hline 4 & 3.367 & 0.001 & -0.840 & 0.401 & -0.643 & 0.521 & & & & & & & 0.403 & 0.687 \\
\hline 5 & 2.101 & 0.036 & -1.989 & 0.047 & -1.906 & 0.057 & -1.322 & 0.186 & & & & & 1.275 & 0.202 \\
\hline \multirow[t]{2}{*}{6} & 0.345 & 0.73 & -3.598 & 0.000 & -3.323 & 0.001 & -3.015 & 0.003 & -2.025 & 0.043 & & & 4.265 & 0.000 \\
\hline & \multicolumn{2}{|c|}{1} & \multicolumn{2}{|r|}{2} & \multicolumn{2}{|c|}{3} & \multicolumn{2}{|c|}{4} & \multicolumn{2}{|c|}{5} & & 6 & \multicolumn{2}{|c|}{ Realized price } \\
\hline
\end{tabular}


Table B.15: Wilcoxon test for Group 6 - Treatment 1

\begin{tabular}{|c|c|c|c|c|c|c|c|c|c|c|c|c|c|c|}
\hline \multicolumn{15}{|c|}{ Group 6 - Treatment 1} \\
\hline Subject & $\mathrm{z}$ & $\mathrm{p}$-value & $\mathrm{z}$ & p-value & $\mathrm{z}$ & $\mathrm{p}$-value & $\mathrm{z}$ & $\mathrm{p}$-value & $\mathrm{z}$ & p-value & $\mathrm{z}$ & $\mathrm{p}$-value & $\mathrm{z}$ & $\mathrm{p}$-value \\
\hline 1 & & & & & & & & & & & & & 3.168 & 0.002 \\
\hline 2 & -0.482 & 0.623 & & & & & & & & & & & 3.421 & 0.001 \\
\hline 3 & -0.177 & 0.859 & 0.181 & 0.857 & & & & & & & & & 3.131 & 0.002 \\
\hline 4 & 0.379 & 0.705 & 0.872 & 0.383 & 0.479 & 0.632 & & & & & & & 1.631 & 0.103 \\
\hline 5 & 0.932 & 0.351 & 1.393 & 0.164 & 1.141 & 0.254 & 0.437 & 0.662 & & & & & 0.037 & 0.97 \\
\hline \multirow[t]{2}{*}{6} & -2.807 & 0.005 & -2.378 & 0.017 & -2.596 & 0.01 & -3.206 & 0.001 & -3.475 & 0.001 & & & 6.125 & 0.000 \\
\hline & \multicolumn{2}{|r|}{1} & \multicolumn{2}{|c|}{2} & \multicolumn{2}{|c|}{3} & \multicolumn{2}{|c|}{4} & \multicolumn{2}{|r|}{5} & & 6 & \multicolumn{2}{|c|}{ Realized price } \\
\hline
\end{tabular}

Table B.16: Wilcoxon test for Group 1 - Treatment 2

\begin{tabular}{|c|c|c|c|c|c|c|c|c|c|c|c|c|c|c|}
\hline \multicolumn{15}{|c|}{ Group 1 - Treatment 2} \\
\hline Subject & $\mathrm{z}$ & $\mathrm{p}$-value & $\mathrm{z}$ & $\mathrm{p}$-value & $\mathrm{z}$ & $\mathrm{p}$-value & $\mathrm{z}$ & $\mathrm{p}$-value & $\mathrm{z}$ & p-value & $\mathrm{z}$ & p-value & $\mathrm{z}$ & $\mathrm{p}$-value \\
\hline 1 & & & & & & & & & & & & & -1.64 & 0.101 \\
\hline 2 & -0.379 & 0.705 & & & & & & & & & & & 0.169 & 0.866 \\
\hline 3 & -0.937 & 0.349 & -0.476 & 0.634 & & & & & & & & & -0.225 & 0.822 \\
\hline 4 & 0.673 & 0.501 & 1.159 & 0.247 & -0.255 & 0.799 & & & & & & & -4.387 & 0.000 \\
\hline 5 & -0.573 & 0.567 & -0.08 & 0.936 & -1.396 & 0.163 & -1.225 & 0.221 & & & & & -1.059 & 0.290 \\
\hline \multirow[t]{2}{*}{6} & -0.556 & 0.578 & 0.097 & 0.923 & 1.432 & 0.152 & 0.901 & 0.368 & 3.051 & 0.002 & & & -0.881 & 0.378 \\
\hline & \multicolumn{2}{|c|}{1} & \multicolumn{2}{|r|}{2} & \multicolumn{2}{|c|}{3} & \multicolumn{2}{|c|}{4} & \multicolumn{3}{|c|}{5} & 6 & \multicolumn{2}{|c|}{ Realized price } \\
\hline
\end{tabular}

Table B.17: Wilcoxon test for Group 2 - Treatment 2

\begin{tabular}{|c|c|c|c|c|c|c|c|c|c|c|c|c|c|c|}
\hline \multicolumn{15}{|c|}{ Group 2 - Treatment 2} \\
\hline Subject & $\mathrm{z}$ & $\mathrm{p}$-value & $\mathrm{z}$ & $\mathrm{p}$-value & $\mathrm{z}$ & $\mathrm{p}$-value & $\mathrm{z}$ & $\mathrm{p}$-value & $\mathrm{z}$ & p-value & $\mathrm{z}$ & p-value & $\mathrm{z}$ & $\mathrm{p}$-value \\
\hline 1 & & & & & & & & & & & & & -2.643 & 0.001 \\
\hline 2 & -0.95 & 0.342 & & & & & & & & & & & 0.347 & 0.729 \\
\hline 3 & -1.566 & 0.117 & -0.704 & 0.482 & & & & & & & & & 0.0556 & 0.955 \\
\hline 4 & -2.079 & 0.038 & -0.436 & 0.663 & 0.583 & 0.56 & & & & & & & 0.422 & 0.673 \\
\hline 5 & 0.879 & 0.379 & 1.355 & 0.175 & 2.059 & 0.04 & 2.702 & 0.007 & & & & & -3 & 0.003 \\
\hline 6 & -1.49 & 0.136 & -0.121 & 0.904 & 0.949 & 0.343 & 0.422 & 0.673 & -2.396 & 0.017 & & & -0.909 & 0.363 \\
\hline & & 1 & & 2 & & 3 & & 4 & & 5 & & 6 & Realiz & ed price \\
\hline
\end{tabular}


Table B.18: Wilcoxon test for Group 3 - Treatment 2

\begin{tabular}{|c|c|c|c|c|c|c|c|c|c|c|c|c|c|c|}
\hline \multicolumn{15}{|c|}{ Group 3 - Treatment 2} \\
\hline Subject & z & p-value & z & p-value & z & p-value & z & p-value & z & p-value & $\mathrm{Z}$ & $\mathrm{p}$-value & z & $\mathrm{p}$-value \\
\hline 1 & & & & & & & & & & & & & 0.262 & 0.793 \\
\hline 2 & 0.904 & 0.366 & & & & & & & & & & & -1.734 & 0.083 \\
\hline 3 & 0.241 & 0.81 & -0.435 & 0.663 & & & & & & & & & -1.659 & 0.097 \\
\hline 4 & 3.427 & 0.001 & 2.436 & 0.015 & 2.848 & 0.004 & & & & & & & -5.783 & 0.000 \\
\hline 5 & 3.969 & 0.000 & 3.186 & 0.001 & 3.762 & 0.000 & 1.73 & 0.083 & & & & & -5.549 & 0.000 \\
\hline \multirow[t]{2}{*}{6} & 0.151 & 0.88 & -0.174 & 0.862 & 0.526 & 0.599 & -2.296 & 0.022 & -2.952 & 0.003 & & & -2.09 & 0.037 \\
\hline & \multicolumn{2}{|r|}{1} & \multicolumn{2}{|c|}{2} & \multicolumn{2}{|r|}{3} & \multicolumn{2}{|r|}{4} & \multicolumn{2}{|c|}{5} & & 6 & \multicolumn{2}{|c|}{ Realized price } \\
\hline
\end{tabular}

Table B.19: Wilcoxon test for Group 4 - Treatment 2

\begin{tabular}{|c|c|c|c|c|c|c|c|c|c|c|c|c|c|c|}
\hline \multicolumn{15}{|c|}{ Group 4 - Treatment 2} \\
\hline Subject & $\mathrm{z}$ & $\mathrm{p}$-value & $\mathrm{z}$ & $\mathrm{p}$-value & $\mathrm{z}$ & $\mathrm{p}$-value & $\mathrm{z}$ & $\mathrm{p}$-value & $\mathrm{z}$ & p-value & $\mathrm{z}$ & $\mathrm{p}$-value & $\mathrm{z}$ & $\mathrm{p}$-value \\
\hline 1 & & & & & & & & & & & & & -2.818 & 0.005 \\
\hline 2 & -0.733 & 0.464 & & & & & & & & & & & 0.394 & 0.694 \\
\hline 3 & -0.489 & 0.625 & 0.281 & 0.779 & & & & & & & & & 0.206 & 0.837 \\
\hline 4 & -0.291 & 0.771 & 0.462 & 0.644 & 0.281 & 0.779 & & & & & & & -2.418 & 0.016 \\
\hline 5 & 0.947 & 0.344 & 1.349 & 0.178 & 1.359 & 0.174 & 1.252 & 0.211 & & & & & -3.74 & 0.000 \\
\hline \multirow[t]{2}{*}{6} & 0.107 & 0.915 & 0.79 & 0.43 & 0.592 & 0.554 & 0.208 & 0.836 & -0.783 & 0.434 & & & -2.878 & 0.004 \\
\hline & \multicolumn{2}{|c|}{1} & \multicolumn{2}{|r|}{2} & \multicolumn{2}{|r|}{3} & \multicolumn{2}{|r|}{4} & \multicolumn{2}{|r|}{5} & & 6 & \multicolumn{2}{|c|}{ Realized price } \\
\hline
\end{tabular}

Table B.20: Wilcoxon test for Group 5 - Treatment 2

\begin{tabular}{|c|c|c|c|c|c|c|c|c|c|c|c|c|c|c|}
\hline \multicolumn{15}{|c|}{ Group 5 - Treatment 2} \\
\hline Subject & $\mathrm{z}$ & p-value & $\mathrm{z}$ & $\mathrm{p}$-value & $\mathrm{z}$ & $\mathrm{p}$-value & $\mathrm{z}$ & $\mathrm{p}$-value & $\mathrm{z}$ & p-value & $\mathrm{z}$ & p-value & $\mathrm{z}$ & p-value \\
\hline 1 & & & & & & & & & & & & & -5.38 & 0.000 \\
\hline 2 & -0.157 & 0.875 & & & & & & & & & & & -5.924 & 0.000 \\
\hline 3 & -0.552 & 0.581 & -0.361 & 0.718 & & & & & & & & & -1.697 & 0.09 \\
\hline 4 & -0.602 & 0.547 & -0.452 & 0.651 & -0.037 & 0.971 & & & & & & & -1.331 & 0.183 \\
\hline 5 & -1.198 & 0.231 & -0.997 & 0.319 & -0.659 & 0.51 & -0.669 & 0.503 & & & & & 5.015 & 0.000 \\
\hline \multirow[t]{2}{*}{6} & -0.469 & 0.639 & -0.318 & 0.751 & 0.06 & 0.952 & 0.141 & 0.888 & 0.803 & 0.422 & & & -1.612 & 0.107 \\
\hline & \multicolumn{2}{|r|}{1} & \multicolumn{2}{|c|}{2} & \multicolumn{2}{|c|}{3} & \multicolumn{2}{|c|}{4} & \multicolumn{2}{|c|}{5} & & 6 & \multicolumn{2}{|c|}{ Realized price } \\
\hline
\end{tabular}


Table B.21: Wilcoxon test for Group 6 - Treatment 2

\begin{tabular}{|c|c|c|c|c|c|c|c|c|c|c|c|c|c|c|}
\hline \multicolumn{15}{|c|}{ Group 6 - Treatment 2} \\
\hline Subject & $\mathrm{z}$ & p-value & $\mathrm{z}$ & p-value & $\mathrm{z}$ & $\mathrm{p}$-value & $\mathrm{z}$ & p-value & $\mathrm{z}$ & p-value & $\mathrm{z}$ & p-value & $\mathrm{z}$ & $\mathrm{p}$-value \\
\hline 1 & & & & & & & & & & & & & -5.933 & 0.000 \\
\hline 2 & -0.355 & 0.738 & & & & & & & & & & & -4.509 & 0.000 \\
\hline 3 & -0.967 & 0.333 & -0.732 & 0.47 & & & & & & & & & 1.828 & 0.068 \\
\hline 4 & -0.184 & 0.854 & 0.141 & 0.888 & 0.83 & 0.401 & & & & & & & -5.737 & 0.000 \\
\hline 5 & -0.398 & 0.69 & -0.127 & 0.899 & 0.679 & 0.497 & -0.231 & 0.817 & & & & & -5.362 & 0.000 \\
\hline \multirow[t]{2}{*}{6} & -0.827 & 0.401 & -0.331 & 0.74 & 0.455 & 0.649 & -0.602 & 0.547 & -0.204 & 0.838 & & & -1.781 & 0.075 \\
\hline & \multicolumn{2}{|c|}{1} & \multicolumn{2}{|c|}{2} & \multicolumn{2}{|r|}{3} & \multicolumn{2}{|c|}{4} & \multicolumn{2}{|r|}{5} & & 6 & \multicolumn{2}{|c|}{ Realized price } \\
\hline
\end{tabular}

